\title{
Physiologically Active Compounds Based on Membranotropic Cage Carriers-Derivatives of Adamantane and Polyhedral Boron Clusters (Review)
}

\author{
V. V. Avdeeva ${ }^{a,}$, , T. M. Garaev ${ }^{b}$, E. A. Malinina ${ }^{a}$, K. Yu. Zhizhin ${ }^{a}$, and N. T. Kuznetsov ${ }^{a}$ \\ ${ }^{a}$ Kurnakov Institute of General and Inorganic Chemistry, Russian Academy of Sciences, Moscow, 119991 Russia \\ ${ }^{b}$ Gamaleya Federal Research Center for Epidemiology and Microbiology, \\ Ministry of Health of Russian Federation, Moscow, 123098 Russia \\ *e-mail: avdeeva.varvara@mail.ru
}

Received June 3, 2021; revised July 20, 2021; accepted July 29, 2021

\begin{abstract}
Data on compounds based on cage structures-boron clusters (polyhedral boron hydrides, carboranes, metallacarboranes) and compounds of the adamantane series, which possess physiological activity, have been generalized. The main emphasis is placed on the antiviral activity of the compounds. The mechanism of the possible action of the replication inhibitors of influenza A virus strains is considered, the molecular model of viroporin inhibitors is discussed. The proposed model consists of a cage hydrophobic core that performs the function of a membranotropic carrier (a boron cluster or adamantane fragment), into which physiologically active functional groups are introduced. The relationship between the structure of the cage compound with the introduced substitute and the biologically active properties of this molecular structure has been analyzed.
\end{abstract}

Keywords: boron cluster anions, closo-borohydride anions, borohydrides, cage structures, adamantane, antiviral activity, amino acids

DOI: $10.1134 / \mathrm{S} 0036023622010028$

\section{INTRODUCTION}

One of the most important tasks facing modern science in the 21st century is the control of socially significant viral infections that have a negative impact on the quality of life of the population. These diseases include viral hepatitis (primarily B and C), HIV infection, influenza $\mathrm{A}$, the new coronavirus infection COVID-19, etc. Vaccination as a method of controlling socially significant infections is not always effective, and often cannot be carried out at all; therefore, in the absence of vaccines, antiviral drugs remain effective.

The search and creation of chemical compounds that can effectively interact directly with a viral particle and thereby inhibit the process of its replication seem to be the most promising method of treatment and prevention of socially significant viral infections. Despite the fact that for the prevention of diseases caused by the influenza virus, WHO prepares an annual forecast for the creation of seasonal vaccines, morbidity and mortality from this disease and complications after it remain high all over the world. In some countries, up to $40 \%$ of the population suffers from seasonal flu every year, and more than 500000 people worldwide die from it every year. Despite worldwide efforts to develop chemotherapy and vaccines, the $2009 / 2010$ pandemic caused by the influenza A(H1N1)pdm2009 virus showed their extremely limited and insufficient effectiveness. New strains of the highly virulent influenza virus could emerge unexpectedly and cause worldwide pandemics with high morbidity and mortality.

To date, almost all strains of the influenza A virus that cause epidemics have proved to be completely resistant to rimantadine. In view of these reasons, the search for new inhibitors of the replication of influenza viruses is an urgent task of modern science. To solve it, it is necessary to analyze the structure of known compounds with physiological properties, and carry out structure-property correlations, which will make it possible to determine the most promising groups of compounds based on cage structures for solving this problem.

This review discusses the pharmacological properties of compounds based on three-dimensional cage inorganic and organic systems consisting of boron atoms (polyhedral boron clusters, Fig. 1) or carbon atoms (adamantane compounds, Fig. 2), respectively.

The van der Waals volumes of carboranes (148, 143, and $141 \AA^{3}$ for ortho-, meta-, and para-carborane, 
(a)

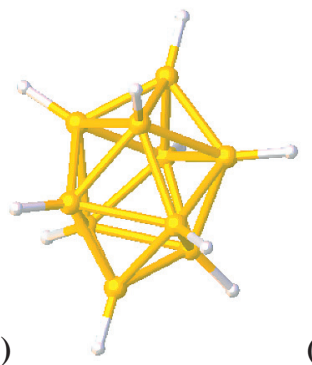

(b)

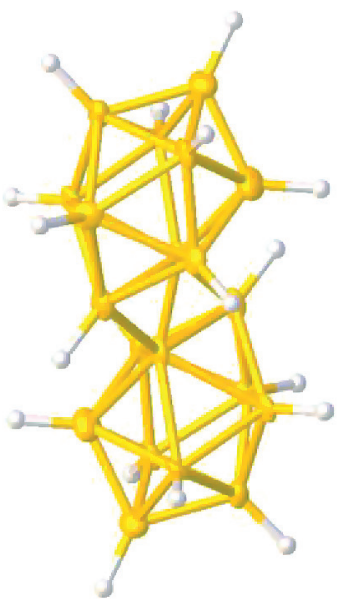

(c)

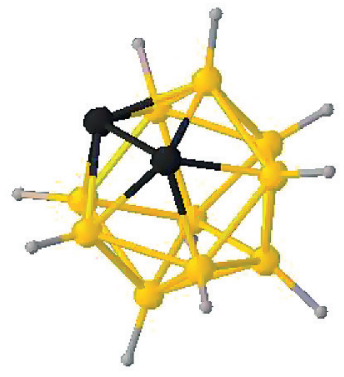

Fig. 1. Structures of boron cluster anions (a) $\left[\mathrm{B}_{10} \mathrm{H}_{10}\right]^{2-}$ and (b) $\left[\mathrm{B}_{20} \mathrm{H}_{18}\right]^{2-}$ and (c) $o$-carborane $\left[\mathrm{C}_{2} \mathrm{~B}_{10} \mathrm{H}_{12}\right]$.

respectively) are comparable to the volume of adamantane $\left(136 \AA^{3}\right)$. The presence of ten $\mathrm{BH}$ groups in a molecule that are unable to form classical hydrogen bonds makes carborane clusters extremely hydrophobic. In this case, the hydrophobicity of the carboranyl fragment is comparable to the hydrophobicity of the adamantyl group and can vary significantly depending on the carborane isomer and the place of attachment of the substitute. In addition, the electronic effect of the carboranyl fragment depends on both the carborane isomer and the position of the substitute and varies from a strong electron-withdrawing one for C-substituted derivatives to a moderate electron-donor one for B-substituted derivatives, which makes it possible to significantly change the properties of compounds based on them. All this makes it possible to consider carboranes as promising pharmacophore groups and use them as analogs of adamantane in the creation of new drugs [1]. In the case of polyhedral boron hydride anions, despite the good water solubility of their salts with cations of alkali and alkaline earth metals, the hydrophobic character of $\mathrm{B}-\mathrm{H}$ groups, which prevents the formation of a stable hydration shell, gives them a latent amphiphilic character [2], which also opens up good prospects for creation of drugs based on them.

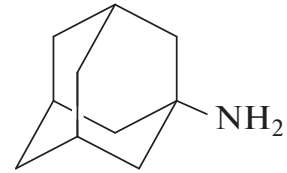

Amantadine

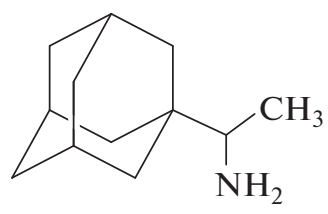

Rimantadine
Boron cluster anions $\left[\mathrm{B}_{n} \mathrm{H}_{n}\right]^{2-}(n=6-12)$ and their analogs (carboranes, metallacarboranes) [3-11] are unique inorganic systems that provide wide possibilities for the creation of derivatives containing various functional groups. For boron cluster anions, there is a possibility of changing the geometric and electronic structure of boron clusters: chemists can use the dianions $\left[\mathrm{B}_{10} \mathrm{H}_{10}\right]^{2-}$ (two-capped Archimedean antiprism), $\left[\mathrm{B}_{12} \mathrm{H}_{12}\right]^{2-}$ (icosahedron), $\left[\mathrm{B}_{20} \mathrm{H}_{18}\right]^{2-}$ (dimeric macropolyhedron), single charged monocarboranes $\left[\mathrm{CB}_{11} \mathrm{H}_{12}\right]^{-}$or neutral dicarboranes $\left[\mathrm{C}_{2} \mathrm{~B}_{10} \mathrm{H}_{12}\right]$ in the design of new compounds. The structures of some of these boron clusters are shown in Fig. 1. The introduction of functional groups into the cluster can lead to a decrease in the system charge and the formation of monoanions or neutral compounds. The possibility of the formation of anionic compounds is very important from the point of view of physiology, since it allows the synthesis of sodium salts of the target compounds, which are highly soluble in water and possess low toxicity. Note that the wide possibilities for varying the structure of boron cluster anions are primarily associated with the three-dimensional aromaticity of these objects [12-14], which allows them to form a large number of stable substituted derivatives with various functional groups.

In turn, organic chemistry provides unlimited possibilities for changing the structure of cage carbon compounds (in our case, compounds of the adamantane series) to tune physiologically significant characteristics of the final compounds. In this work, adamantane derivatives with antiviral activity are considered.

The data presented in this review make it possible to trace the change in the physiologically active properties of compounds depending on changes in their structure, to determine the effect of the nature of the substituent introduced into the organic or inorganic

Fig. 2. Structure of amantadine and rimantadine. 


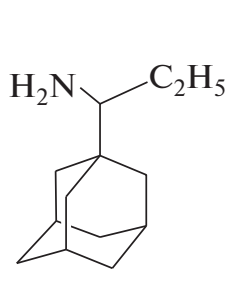

(a)

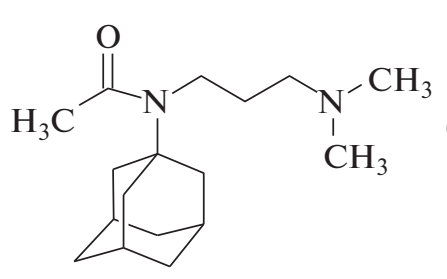

(b)

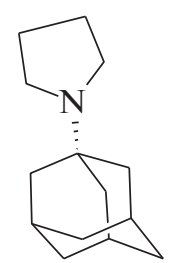

(e)

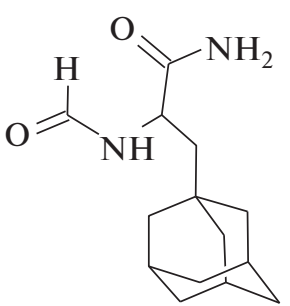

(c)

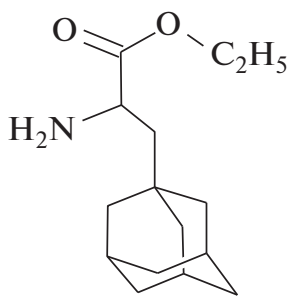

(d)

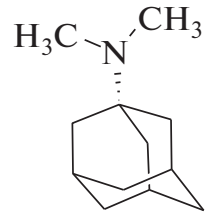

(f)

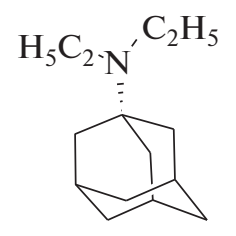

(g)

Fig. 3. Derivatives of aminoadamantane possessing antiviral properties.

cage on the properties of the compound, and also to suggest the most promising area of changes in the structure of cage derivatives for the search for new physiologically active drugs, primarily promising in inhibiting influenza viruses.

\section{ADAMANTANE-TYPE DERIVATIVES WITH ANTI-VIRAL ACTIVITY}

Adamantane derivatives are the basis for numerous compounds, and their discovery laid the foundation for a new field of chemistry that studies approaches to synthesis, as well as the physicochemical and biological properties of organic polyhedral compounds that have practical application in the pharmaceutical industry $[15,16]$. Adamantane derivatives are in demand in many areas of medicine, including systemic and local therapy. The lipophilicity of the adamantane nucleus ensures interaction both with biological membranes containing a lipid layer and with hydrophobic regions of protein molecules that are part of the receptor structure. When adamantane fragments are introduced into the structure of pharmacophores, the pharmacokinetic profiles of modified drugs are improved [17, 18]. Simple aminoadamantanes (amantadine, rimantadine) have taken a reliable place in the pharmaceutical market, showing their effectiveness in the treatment of viral diseases such as influenza A, herpes, hepatitis C, and HIV [19]. Development of pyrazole derivatives of adamantane against FMD infection is also underway [20]. The researchers found that the release of virions from cells infected with the FMD virus was inhibited by amantadine, which is an inhibitor of the function of viroporin M2 of the influenza A virus [21].

In addition to the influenza virus, rimantadine inhibits the reproduction of the Sindbis virus, since, being a weak lipophilic base, it can increase the $\mathrm{pH}$ of endosomal contents and prevent the deprotonization of the virus [22]. Adaprominum (Fig. 3a) [23] is active against influenza $\mathrm{A}$ and $\mathrm{B}$ viruses, but it is more toxic than rimantadine. The antiviral drug tromantadine (Fig. 3b) is used in the form of ointments and is active against herpes simplex viruses of types 1 and 2 and herpes simplex virus Zoster (herpes simplex virus of type 3) [24]. Compounds of adamantane- $\alpha$-amino acids, in which adamantane is linked to the carbon of the side chain of the amino acid by the $\mathrm{C}-\mathrm{C}$ bond, and the carboxyl group of the amino acid is represented by an ester or amide group (Figs. 3c and 3d), are active against the Sindbis virus (selectivity index (SI) is 2) and influenza A virus at the level of rimantadine. Alkyl derivatives of aminoadamantane are also active against influenza A S-15 virus (Figs. 3d-3g) [25].

The authors [26] showed that triazole and tetrazole derivatives of adamantanes have a high level of in vitro antiviral activity against laboratory and circulating seasonal influenza A viruses and moderate activity against the pandemic A(H1N1)pdm2009 strain. Moreover, tetrazole derivatives of adamantanes are more active than their triazole homologues [27]. Compounds of the azolo-adamantane class have a high level of in vitro antiviral activity against rimantadine-resistant strain A/PR78/34(H1N1) (SI > 8) [26, 27]. However, the level of activity is highly dependent on the chemical structure. Thus, among the derivatives of 1,2,4-triazoles, compound 1-(3-chloro-1,2,4triazol-1-yl)-3-(1-aminoethyl-1) adamantane (Fig. 4a) exhibits significant activity against influenza A virus $(\mathrm{SI}=10)$, while adamantyl derivatives of tetrazole (Figs. 4b-4d) demonstrate a high level of activity against the influenza virus. It was found that the position of the adamantyl moiety in the tetrazole ring can play an important role in enhancing the activity of compounds of this class. 


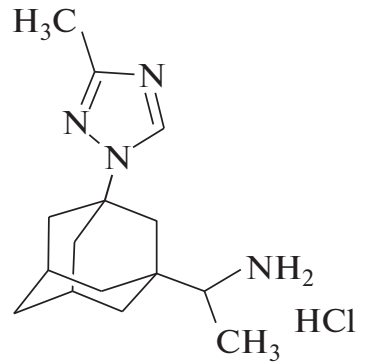

(a)

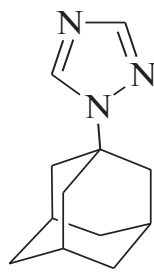

(b)

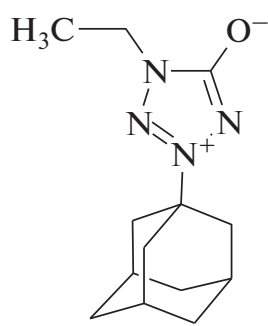

(c)

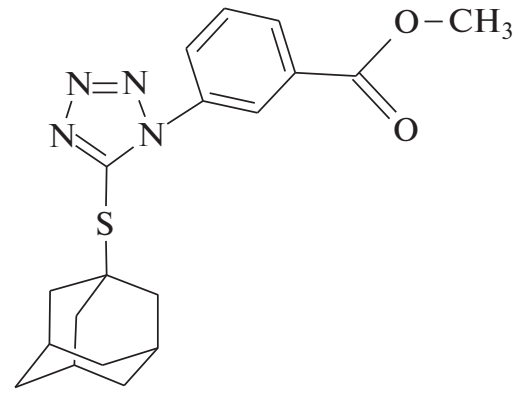

(d)

Fig. 4. Triazole and tetrazole derivatives of adamantanes with in vitro antiviral activity against influenza A.

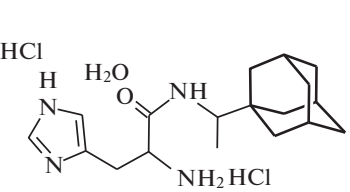

(a)

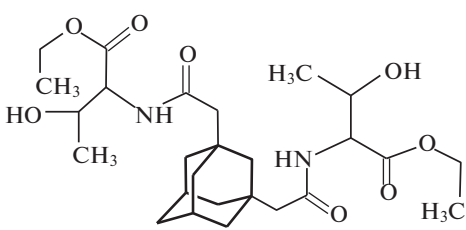

(b)

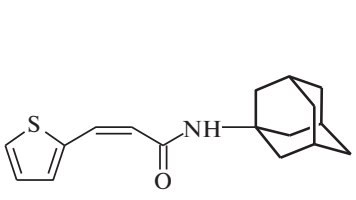

(c)

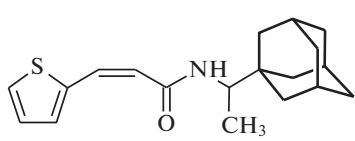

(d)

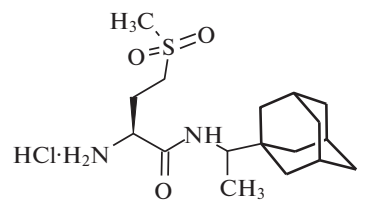

(e)

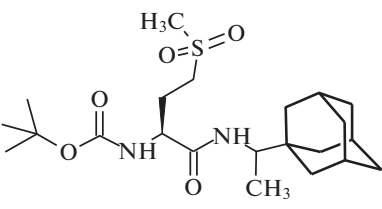

(f)

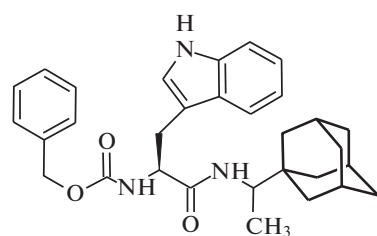

(g)

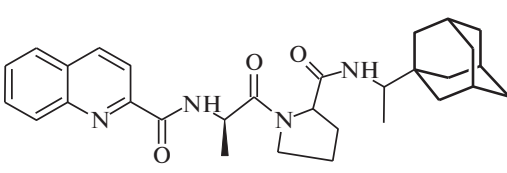

(h)

Fig. 5. $\mathrm{N}$-Acyl derivatives of aminoadamantanes with anti-influenza activity against virus strains resistant to rimantadine.

A method was proposed to overcome the resistance of influenza A viruses to adamantane series drugs by introducing new functional groups (carboxyl, hydroxyl, imidazole, indole, etc.) into the aminoadamantane carbocycle using amino acids, peptides, or other physiologically important compounds [28]. The resulting series of carbocyclic derivatives of amino acids and peptides is capable of inhibiting highly pathogenic strains of influenza A viruses, including A/H1N1pdm09, A/H5N1, A/H3N2, etc. (Fig. 5). Moreover, the toxicity of the compounds was not higher than rimantadine, and for a number of compounds is was even lower [29]. The compounds have a chemical therapeutic index (SI) from 8 to 120 and exhibit virucidal properties against the pandemic influenza A/H5N1 virus. In Vero-E6 cell cultures (continuous cultures of green monkey kidney cells, clone 6) and SPEV (pig embryonic kidney cell line), the decrease in the infectious titer of the virus was from 3 to 5 logarithms $(\log )$ relative to the control.

The combination of rimantadine with the histidine amino acid residue (Fig. 5a) is highly effective in vitro against the avian influenza virus A/duck/Novosibirsk/56/05 (H5N1), which has pandemic potential. The compound effectively protects the monolayer of Vero-E6 cells in various dosage regimens, and the 50\% inhibitory dose averages $0.5 \mathrm{mM}$. The antiviral activity of this compound is superior to the well-known domestic drug Arbidol [30]. For the compound (Fig. 5a), the mechanism of action in silico and in vitro was determined by comparing the results of molecular docking and antiviral properties of artificially created 
mutants of the A/PuertoRico/8/34 (H1N1) virus with point amino acid substitutions in the transmembrane region of the M2 protein [31].

The 1,3-adamantanediacetic acid derivative with two residues of ethyl threonine ester $N, N$-1,3-diacyladamantyl diethyltreonate (Fig. 5b) highly selectively inhibits the reproduction of influenza $\mathrm{A}$ virus and is effective against strains resistant to rimantadine hydrochloride [32]. Compounds containing thienylcarboxylic acids (Figs. 5c and 5d) suppress the reproduction of the influenza A/IIV-Orenburg/83/2012(H1N1)pdm09 virus. The compound with 1-aminoadamantane has the lowest inhibitory dose ( $\mathrm{ID}_{50}$ is $\left.1 \mathrm{mM}\right)$ (Fig. 5c). Compounds of rimantadine with the methionine sulfone residue effectively inhibited the reproduction of the reference strain of the influenza A/California/07/2009 virus (Figs. 5e and $5 \mathrm{f}$ ). The compound shown in Fig. $5 \mathrm{f}$ with the Bocblocked amino group has the highest antiviral effect $\left(\operatorname{ID}_{50} 0.65 \mu \mathrm{M}\right)$. The molecule of the $N$-acyladamantyl peptide compound with rimantadine is larger than the adamantyl amino acid molecule, but does not exceed the inner pore diameter of the M2 channel of the influenza virus. The combination of rimantadine with quinaldyl-Ala-Pro-OH (Fig. 5h) has a stable percentage of suppression of the cytopathic effect of the reference strain of influenza A/California/07/2009 (ID50 0.74 mM) [33].

The authors [34] synthesized adamantane derivatives (rimantadine and amantadine) modified with glycyl-thiazole (Figs. 6a, 6b, 6e, and 6f) and glycylthiazole-thiazole molecules (Figs. 6c and 6d) and studied their antiviral and antimicrobial activity. Compounds with the blocked amino group of glycine Boc-Gly-Thz-amantadine and Boc-Gly-Thz-rimantadine (Figs. 6a and $6 \mathrm{~b})$ were dissolved in TFA $(20 \mathrm{~mL})$ to remove the protective Boc-group and were also used in tests for antiviral and fungicidal activity. Compounds with a dithiazole motif contained a protective Fmoc group (Fig. 6c). Tests have shown that the presence of a spatially bulky Fmoc group does not improve the antiviral effect of aminoadamantanes: compounds protected at the $\alpha$-amino group do not exhibit any antiviral activity. An analogue of rimantadine with a free $\alpha$-amino group, including a thiazole unit (Fig. 6f), demonstrated moderate activity against influenza A/Hongkong/68(H3N2) virus. In contrast, the analog of amantadine with a free $\alpha$-amino group, which includes a thiazole motif (Fig. 6e), does not exhibit antiviral effect. The results show that neither the thiazole ring nor the free amino group is critical for antiviral activity. The compound Gly-Thz-rimantadine (Fig. 6f) in two tested concentrations (10 and $60 \mathrm{mM}$ ) showed very good antifungal activity against the model strain of fungus Yarrowia lipolytica.

Other compounds have no antifungal activity. All compounds show no activity against model strains of Gram-positive and Gram-negative microorganisms.
Spiroderivatives of adamantane are capable of inhibiting the influenza $\mathrm{A}(\mathrm{H} 1 \mathrm{~N} 1), \mathrm{A}(\mathrm{H} 2 \mathrm{~N} 2)$, and $\mathrm{A}(\mathrm{H} 3 \mathrm{~N} 2)$ strains at concentrations of $\sim 55 \mu \mathrm{g} / \mathrm{mL}$. Compounds shown in Fig. 7 also showed activity at the level of $115 \mu \mathrm{g} / \mathrm{mL}$ against HIV-1 in vitro; however, these compounds were not effective against HIV-2. Moreover, the activity of anti-HIV-1 was manifested only for the spiro-fused six-membered analogs, but was not detected for the spiro-fused five-membered analogs [35].

In recent years, scientists have been interested in the synthesis of adamantyl-containing nucleic bases and related compounds and the study of their ability to inhibit HIV-1 replication. In particular, such derivatives are capable of facilitating drug transport across biological membranes. A derivative of 3'-azido-3'deoxythymidine (azidothymidine, AZT), containing an adamantane fragment at the 5 '-nucleoside position (Fig. 8a), more easily as compared to native AZT penetrates into the brain tissue, where the HIV virus directly damages the brain membranes and tissue [36]. There are other AZT derivatives modified with the adamantane molecule [37], such as the 3'-(1-adamantyl)thioureido derivative of thymidine (Fig. 8b) and the derivative at the phosphate group obtained by the interaction between (1-adamantylphosphonyl)phosphate and azidothymidine monophosphate (Fig. 8c).

Like the M2 proton channel of the influenza A virus, the $\mathrm{p} 7$ ion channel plays an important role in the reproduction of hepatitis $\mathrm{C}$ virus ( $\mathrm{HCV}$ ) viral particles. The non-structural HCV p7 protein consists of 63 aminoacid residues and has two transmembrane domains (TM1 and TM2) [38]. Six p7 subunits form a hexameric aggregate localized mainly in intracellular membranes, which, in the course of in vitro experiments, exhibits the function of the ion channel necessary for viral assembly and its optimal exit from infected cells by changing the acid-base balance of intracellular vesicles [39]. It was previously determined that the functioning of the $\mathrm{p} 7$ ion channel can be blocked by small inhibitor molecules, in particular, adamantane derivatives, which leads to a significant decrease in the reproduction of viral particles [40].

Larger structures of carbocyclic peptide derivatives are active in inhibiting hepatitis $\mathrm{C}$ virus replication [4]. The aminoadamantane carbocycle molecule, provided with additional functionally active groups, in the process of interacting with the transmembrane domain of the $\mathrm{HCV} \mathrm{p} 7$ protein is capable of disrupting the process of ion transport across the membrane. The source of such functionally active groups can be peptide residues attached to rimantadine by peptide synthesis methods [41].

The synthetic compounds shown in Fig. 9, exhibit a significantly lower toxic effect compared to rimantadine in the SPEV cell culture. Moreover, the compound (Fig. 9b) has the lowest toxicity, and also exhibits virucidal activity against HCV. The decrease in the 
<smiles>CC(C)(C)OC(=O)NCc1ncc(C(=O)NC23CC4CC(CC(C4)C2)C3)s1</smiles><smiles>CC(NC(=O)c1cnc(CNC(=O)OC(C)(C)C)s1)C12CC3CC(CC(C3)C1)C2</smiles>

(b)

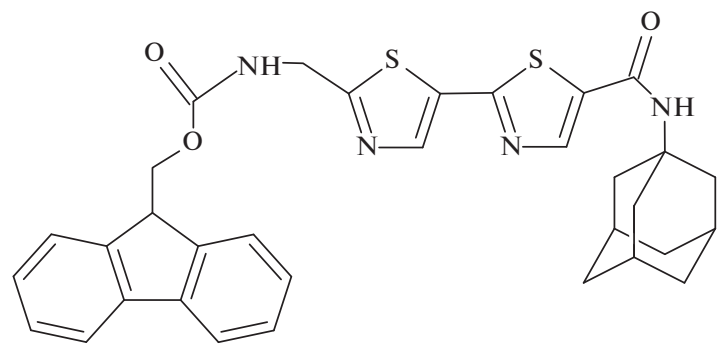

(c)<smiles>CC(NC(=O)c1cnc(-c2cnc(CNC(=O)OCC3c4ccccc4-c4ccccc43)s2)s1)C12CC3CC(CC(C3)C1)C2</smiles>

(d)<smiles>NCc1ncc(C(=O)NC23CC4CC(CC(C4)C2)C3)s1</smiles>

(e)

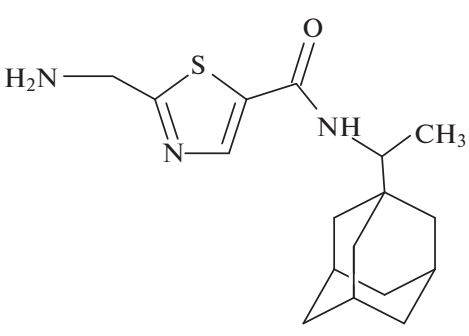

(f)

Fig. 6. Derivatives of adamantane containing a thiazole motif.

infectious titer occurs by more than five decimal logarithms (10000 times) in relation to the in vitro viral control.

The main mechanism of antiviral action seems to be similar to the action of amantadine on the HCV p7 ion channel [42]. At least the HCV p7 ion channel is the most likely target for the proposed compounds. The residue of the carbocycle of adamantane in this case obviously plays the role of a carrier to which the functionally active group of the corresponding peptide is "attached." This is consistent with the proposed

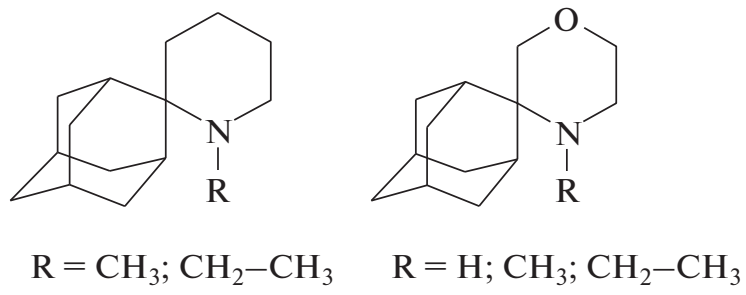

Fig. 7. Spiroderivatives of adamantane with antiviral activity against influenza A and HIV-1. design of a universal molecular model for a viroporin inhibitor.

\section{Derivatives of Boron Cluster Anions Possessing Physiological Activity}

Interest in the chemistry of boron cluster anions results primarily from the possibility of using compounds based on boron clusters in medicine. This line of research includes the search for ways to synthesize substituted derivatives of boron cluster anions to obtain new drugs for diagnostics and therapy of oncological diseases (in particular, for boron neutron capture therapy and binary therapy, etc. [43-45]), contrast agents for MRI diagnostics [46], preparation of compounds with antimicrobial and antiviral activity [47], etc.

One of the most important requirements for the preparation of drugs with pharmacological activity is the selectivity of delivery of the boron preparation to the biological target; therefore, the strategy of creating new boron-containing substances for therapeutic purposes is based on the introduction of effective transport groups into the boron cluster. To implement this approach, it is necessary to develop methods that 


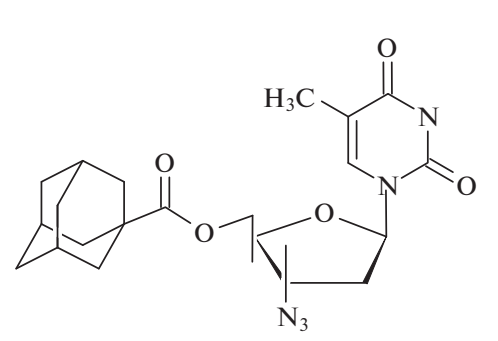

(a)

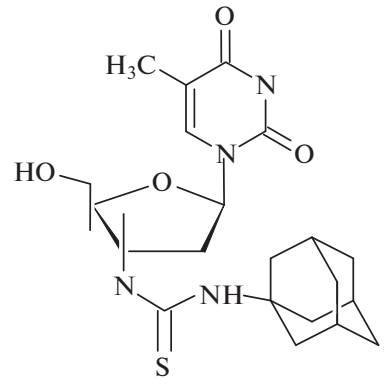

(b)

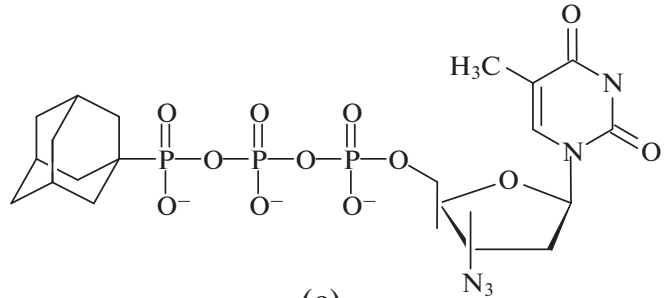

(c)

Fig. 8. Adamantyl-containing derivatives of AZT capable of inhibiting HIV replication.<smiles>CC(NC(=O)CNC(=O)CNC(=O)C(CCCCNC(=O)OC(C)(C)C)NC(=O)OC(C)(C)C)C12CC3CC(CC(C3)C1)C2</smiles>

Boc-Lys(Boc)-Gly-Gly-Rem

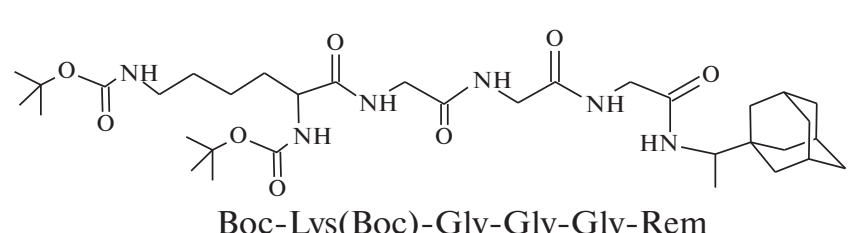

(b)

(a)

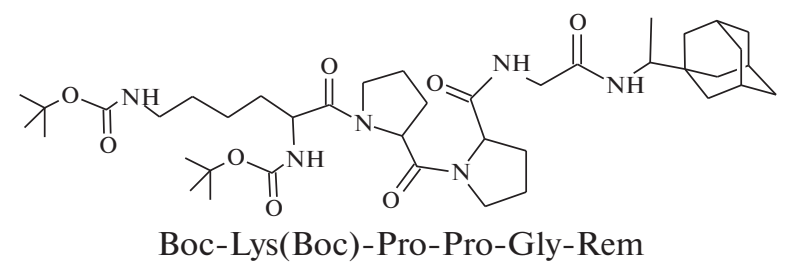

(c)

Fig. 9. Structural formulas of 1-(1-adamantyl)ethylamide- $N, N$-di-tert-butyloxycarbonyl peptides capable of inhibiting HCV replication in vitro.

make it possible to modify the compounds of boron cluster anions under mild conditions and to obtain products that are stable in biological media.

The introduction of boron cluster anions into biomolecules leads to a sharp change in the hydrophilic and lipophilic properties, which makes it possible to regulate the behavior of the obtained compounds in biological media. closo-Decaborate and closo-dodecaborate anions $\left[\mathrm{B}_{10} \mathrm{H}_{10}\right]^{2-}$ and $\left[\mathrm{B}_{12} \mathrm{H}_{12}\right]^{2-}$ exhibit hydrophilic properties, while dicarbadecaborane $\left[\mathrm{C}_{2} \mathrm{~B}_{10} \mathrm{H}_{12}\right]$ has a pronounced hydrophobic character, which allows carborane-containing biomolecules to effectively bind to hydrophobic receptors [48]. The creation of biomolecules containing boron cluster anions makes it possible to achieve increased in vitro stability of the obtained compounds.

The most studied area of application of boron cluster anions and carboranes is their use for boron neutron capture therapy (BNCT). BNCT is based on the nuclear reaction of a stable isotope boron-10 with thermal neutrons $\left(E_{n}=0.025 \mathrm{eV}\right.$, the capture cross section of ${ }^{10} \mathrm{~B}$ is 3890 barn). The particles formed as a result of the ${ }^{10} \mathrm{~B}\left(n_{\mathrm{th}} \mid \alpha, \gamma\right){ }^{7} \mathrm{Li}$ reaction are helium nuclei (alpha particles) and lithium-7 recoil nuclei, which have a high linear energy loss in tissues ( 200 and $350 \mathrm{keV} / \mu \mathrm{m}$, respectively) and a small total range $(\sim 14 \mu \mathrm{m})$, commensurate with the diameter of one cell. In the case of selective accumulation of boron-10 in tumor cells, a selective radiation effect can be achieved at the cellular level. Ideally, only tumor cells are destroyed, including arbitrarily small metastases, without damaging normal tissues in the irradiated volume. The key task remains to create boron-containing preparations capable of selectively delivering a therapeutic amount of boron10 to malignant tumor cells, ensuring its optimal microdistribution, and remaining in cells for a period of time necessary for irradiation. Studies in this area are being carried out intensively (see, for example, [49-54]) and requires separate consideration, which is beyond the scope of this review. Boron cluster anions are suitable for achieving these goals due to their high chemical and biological stability, high boron content in the molecule, low toxicity, and the possibility of 
(a)

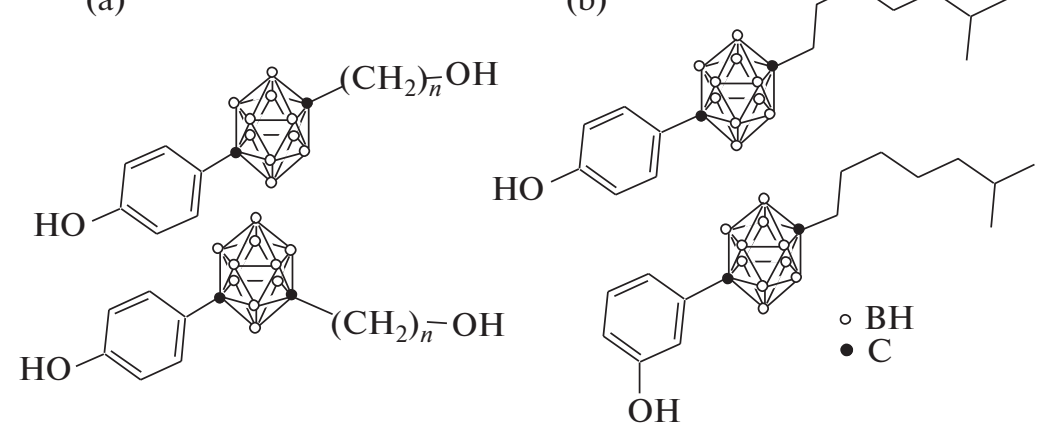

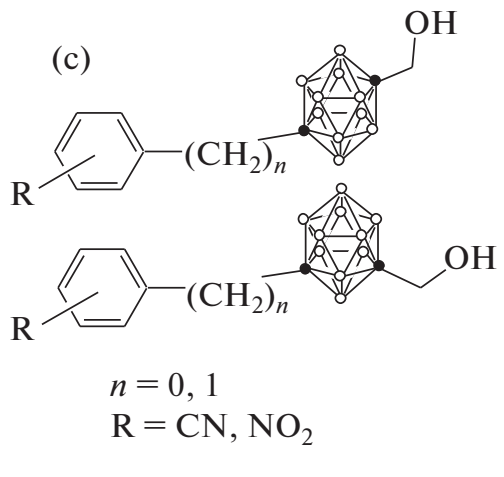

Fig. 10. Carborane-containing analogs of (a) 17-estradiol, (b) cholesterol, (c) testosterone, and (d) agonists and (e) antagonists of the estrogen receptor.

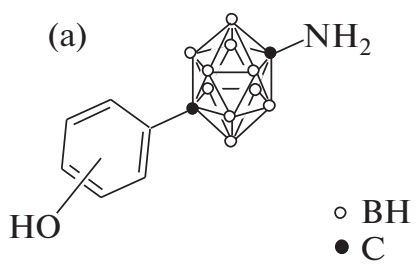

(b)

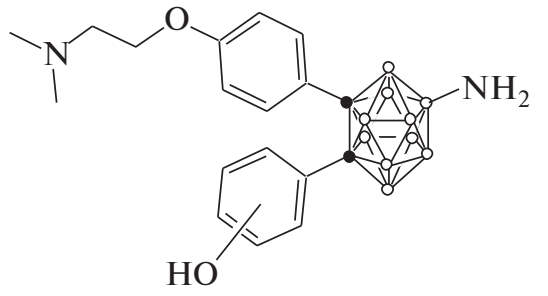

Fig. 11. Carborane-containing (a) agonists and (b) antagonists of the estrogen receptor.

obtaining water-soluble compounds (for example, sodium salts of derivatives of boron cluster anions). It should be noted that the dimeric boron cluster anion [trans $\left.-\mathrm{B}_{20} \mathrm{H}_{18}\right]^{2-}[55-57]$ contains twenty boron atoms (Fig. 1) per anion and has a significant advantage over many other borohydrogen anions and heteroboranes in the preparation of compounds suitable for BNCT purposes. In this regard, the study of the reactivity of the dimeric anion $\left[\text { trans }-\mathrm{B}_{20} \mathrm{H}_{18}\right]^{2-}$ and its derivatives is of particular interest.

A large number of carborane analogs of various steroid compounds have been synthesized. Steroids often act as hormones that interact with specific receptors. The effectiveness of their binding to receptors depends on the hydrophobic nature of steroids. The introduction of a carborane fragment into a biomolecule contributes to a strong increase in its hydrophobicity, which leads to an increase in the biological activity of these compounds. In particular, carborane-containing analogs of 17-estradiol (Fig. 10a) [58], cholesterol (Fig. 10b) [59], and 4,5-2H-dihydrotestosterone (Fig. 10c) [60] were synthesized.

A number of carborane derivatives have been tested as potential antagonists [58, 61] and agonists [58, 62] of the estrogen receptor (Figs. 11a, 11b). The main emphasis was placed on the synthesis of estradiol analogs containing a cluster core, which allowed the resulting compounds to exhibit strong hydrophobic interactions with the estrogen receptor. The effect of the type of carborane isomer and the nature of the substituent in the carborane cluster on biological activity was studied.

Carborane analogs of retinoids [63, 64] are of interest in the field of dermatology and oncology. The introduction of a bulky hydrophobic carborane group into retinobenzoic acids promotes the appearance of an antagonistic effect. The biological properties of various diphenylamines associated with carboranes have been synthesized and studied (Fig. 12). A number of compounds exhibited strong agonistic activity at concentrations of $10^{-8}-10^{-9} \mathrm{~mol}$. The results show that carboranes are useful as hydrophobic fragments of biologically active molecules.

New types of adenosine and 2'-deoxyadenosine derivatives containing boron clusters at the C2', N6, or C8 positions have been synthesized [65]. Selected compounds are shown in Fig. 13. The effect of these modified compounds on platelet function has been studied. Modification of adenosine at the $\mathrm{C} 2$ position with para-carborane results in effective inhibition of platelet function, including aggregation, protein secretion, and P-selectin expression induced by thrombin or ADP. The results obtained contribute to the creation of a new class of adenosine analogs that modulate the activity of human blood platelets.

Another area of application of compounds based on boron cluster anions is the creation of bioconjugates based on carbaboranyl phosphonates [66, 67]. There are two approaches to the synthesis of these biomolecules: the creation of compounds in which the 


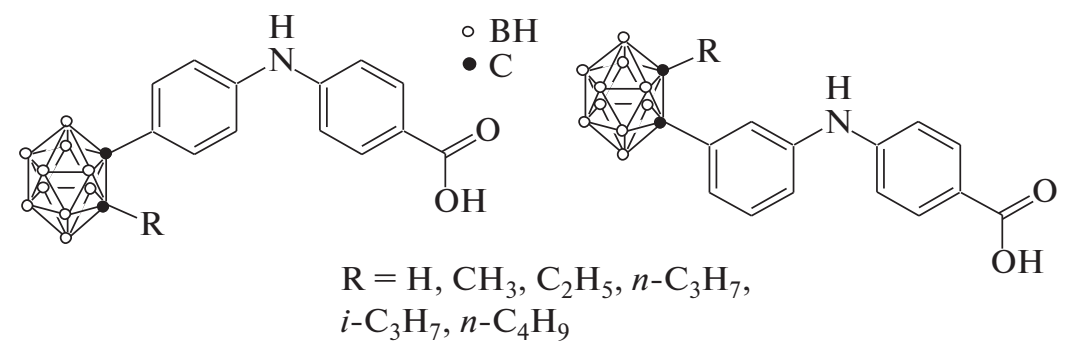

Fig. 12. Carborane-containing derivatives of retinoids.

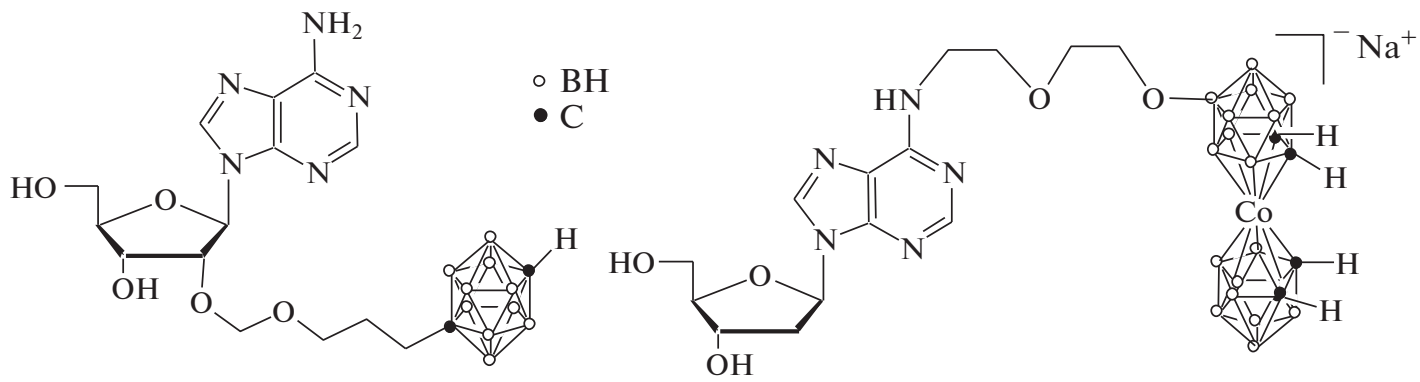

Fig. 13. Carborane-containing derivatives of adenosine and 2'-deoxyadenosine.

phosphonate group is directly linked to the carborane cluster (Figs. 14a, 14b) or is separated from the cluster by a spacer group (Fig. 14c). Carboboranyl phosphonates exhibit high anticholinesterase activity. Compounds in which the phosphonate group is directly linked to carborane exhibit gametocidal activity, while molecules in which the phosphonate group is connected to the cluster via sulfur or selenium atoms exhibit bactericidal activity. Carboboranyl mono- and diphosphonates linked in oligonucleotide sequences can serve as oligonucleotide therapy agents due to increased resistance to nuclease uptake.

The antimicrobial effect of some derivatives of boron cluster anions and carboranes has been studied. In [68], a number of derivatives of $o$-carboranes and anionic dicarbollides of the nido-type were synthesized, and their antimicrobial activity was studied (Fig. 15). Almost all of the studied monoanions of the dicarbollide are active in vitro against fungi Candida albicans, Aspergillus fumigatus and Tricophyton asteroides, as well as against Gram-positive bacteria. From the structure-activity ratios, the authors concluded that the introduction of lipophilic alkyl groups $\left(\mathrm{C}_{5}-\mathrm{C}_{17}\right)$ or $o$-carboranyl groups to hydrophilic dicarbollide anions leads to antimicrobial activity, while most carborane derivatives exhibit low activity, with the exception of amino and chlorine derivatives, which appear to be active against Tricophyton asteroides and Grampositive bacteria.

The authors [69] studied the activity of $o$-carboranylalanine (Fig. 16), a highly lipophilic analog of the amino acid phenylalanine, against various plant pathogens. $o$-Carboranylalanine showed high activity (MIC values fall in the range from 0.00015 to $0.32 \mu \mathrm{M}$, which is more than 1000 times higher than that of tridemorph, a fungicide of a selective zoospore inhibitor) against all asexual spores of Plasrnopara halstedii.

Metallocarborane derivatives have been synthesized (Fig. 16b) with antibacterial activity against methicillin-resistant Staphylococcus aureus, Y. enterocolitica, and Pseudomonas aeruginosa [70, 71].

A number of isoniazid derivatives of carborane containing 1,2-dicarba-closo-dodecaborane, 1,7dicarba-closo-dodecaborane, 1,12-dicarba-closododecaborane, or 7,8-dicarba-nido-undecaborate anion were synthesized [72]. The compounds were tested in vitro against the Mycobacterium tuberculosis (Mtb) H37Rv strain and its mutant ( $\Delta \mathrm{katG})$, deficient in catalase-peroxidase synthesis (KatG). $N^{\prime}-((7,8-$ Dicarba-nido-undecaboranyl)methylidene)isonicotinohydrazide (Fig. 17a) showed the highest activity against the wild-type Mtb strain $\left(\mathrm{MIC}_{99}=0.33 \mu \mathrm{M}\right.$ (Mtb), $\mathrm{MIC}_{99} \geq 660 \mu \mathrm{M}(\Delta \mathrm{katG})$ ).

In [73], the antimicrobial properties of cobalt bisdicarbollide $\left[3,3^{\prime}-\mathrm{Co}\left(1,2-\mathrm{C}_{2} \mathrm{~B}_{9} \mathrm{H}_{11}\right)_{2}\right]^{-}$and sodium salts of its derivatives $\left[3,3^{\prime}-\mathrm{Co}\left(8-\mathrm{R}\left(\mathrm{CH}_{2} \mathrm{CH}_{2} \mathrm{O}\right)_{2}-1,2-\right.\right.$ $\left.\left.\mathrm{C}_{2} \mathrm{~B}_{9} \mathrm{H}_{10}\right)\left(1^{\prime}, 2^{\prime}-\mathrm{C}_{2} \mathrm{~B}_{9} \mathrm{H}_{11}\right)\right]^{-} \quad\left(\mathrm{R}=-\mathrm{OOCCH}_{3}\right.$, $-\mathrm{OCH}_{3}$, and $-\mathrm{OCH}_{2} \mathrm{CH}_{3}$ ) were studied. The results showed that among the compounds studied, compounds with $\mathrm{R}=\mathrm{OCH}_{2} \mathrm{CH}_{3}$ (Fig. 17b) exhibit the highest antimicrobial activity, which is equal to or even higher than the activity of the commercially available broad-spectrum antibiotic thiamphenicol. It was 


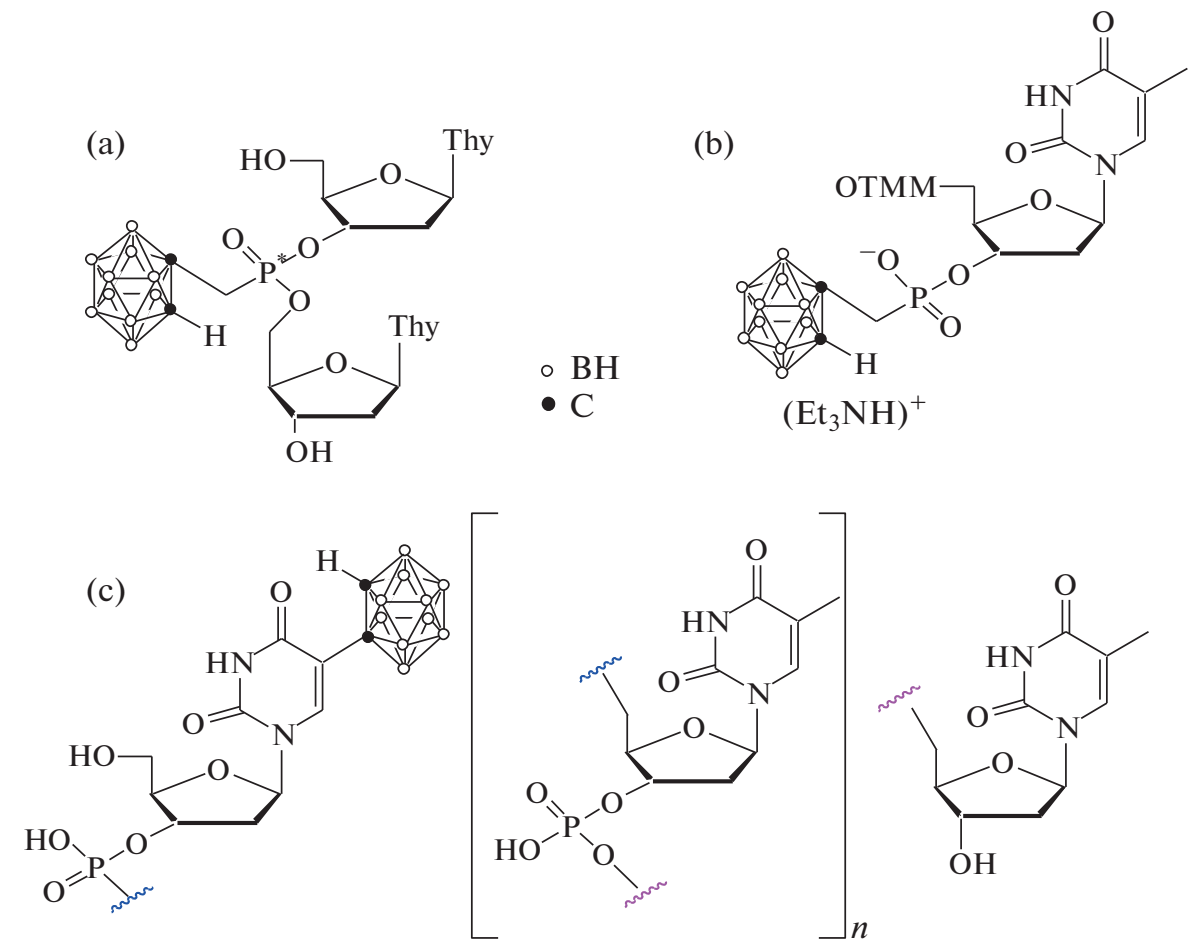

Fig. 14. Carborane-containing phosphonates.

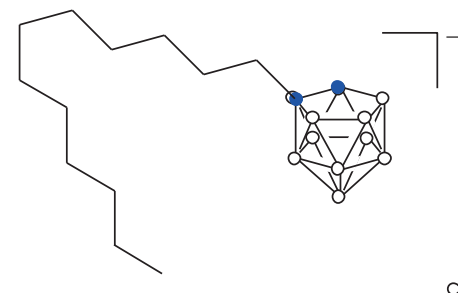

(a)

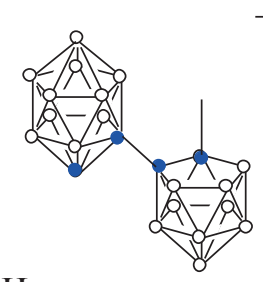

(b)

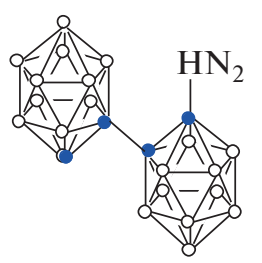

(c)

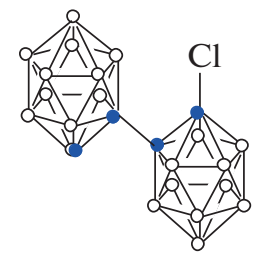

(d)

Fig. 15. Derivatives of carboranes and anionic dicarbollides of nido-type with antimicrobial activity.

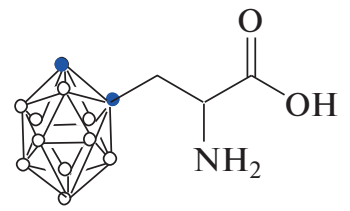

(a)

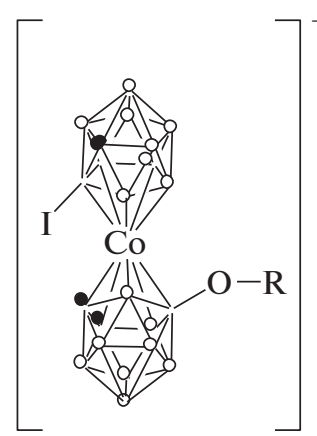

(b)

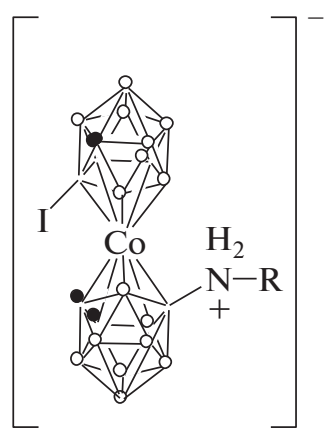

Fig. 16. Structure of (a) $o$-carboranylalanine and (b) metallacarborane derivatives active against $Y$. enterocolitica and $P$. aeruginosa. 

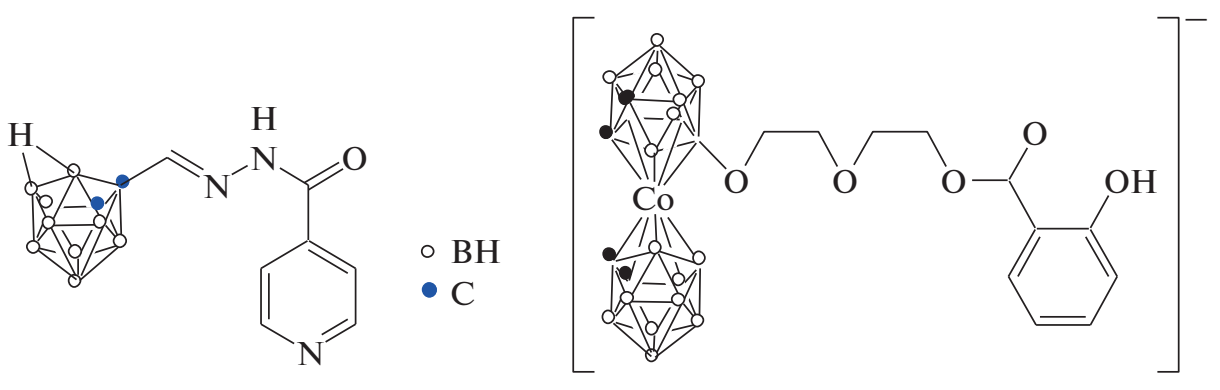

(a)

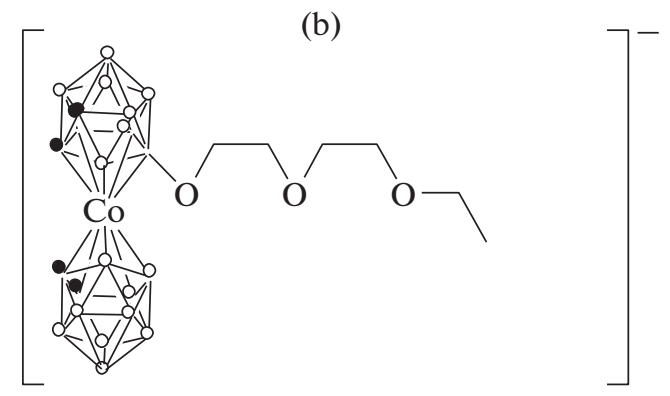

Fig. 17. Structures of (a) isoniazid derivative 7,8-dicarba-nido-undecaborane and (b) bis-dicarbollide cobalt derivatives 3,3'$\left.\mathrm{Co}\left(8-\mathrm{R}\left(\mathrm{CH}_{2} \mathrm{CH}_{2} \mathrm{O}\right)_{2}-1,2-\mathrm{C}_{2} \mathrm{~B}_{9} \mathrm{H}_{10}\right)\left(1^{\prime}, 2^{\prime}-\mathrm{C}_{2} \mathrm{~B}_{9} \mathrm{H}_{11}\right)\right]^{-}$.

found that cobalt bis-dicarbollide exhibits comparatively lower antibacterial and antifungal properties compared to its derivatives. From a practical point of view, the authors emphasize that methicillin-resistant $S$. aureus (TSA MRSA), multi-resistant $P$. aeruginosa, and Candida spp. are sensitive to compounds indicated in Fig. 17b.

The authors [74] synthesized thymine derivatives containing ortho-carborane, para-carborane, and nido-carborane clusters (Fig. 18). It was found that the obtained compounds are inhibitors of bacterial enzymes and can be used as new anti-tuberculosis drugs.

A number of amides and derivatives of diboraoxazoles containing closo-dodecaborate anion (Fig. 19), which can be considered as 3D analogs of benzoxazoles, were synthesized and investigated for antimicrobial activity [75] against Gram-negative (Neisseria gonorrhoeae) and Gram-positive ( $S$. aureus and Enterobacter faecalis) bacteria. Diboraheterocycles showed high specific activity against $N$. gonorrhoeae, but low activity against gram-positive bacteria.

A series of new analogues of penicillin $\mathrm{G}$ containing lipophilic ortho-, meta-, or para-carborane instead of the phenyl ring has been synthesized [76]. Penicillin $\mathrm{G}$ analogs were obtained by amidation of 6-aminopenicylanic acid (6-APA) with active $\mathrm{N}$-succinimidyl esters containing ortho-, meta- or para-carborane. Alternatively, analogs containing ortho- or para-carborane have been synthesized using ortho- or paracarborane acid chlorides. The compounds thus obtained were tested in vitro against the Gram-positive bacteria $S$. aureus and the Gram-negative bacteria
Klebsiella pneumoniae, E. cloacae, Acinetobacter baumanii, and $P$. aeruginosa. The most potent inhibitor of the growth of Gram-positive bacteria was the compound containing the para-carborane cluster (Fig. 20) (S. aureus, MIC $64 \mu \mathrm{g} / \mathrm{mL}$ ). Compounds containing ortho- or meta-carborane, respectively, were less active against $S$. aureus.

A series of $N$-alkylammonium derivatives of 8 diethylene glycol-bis-dicarbollide cobalt (Fig. 21) was obtained by a direct method [77]. The antibacterial and antifungal activity of seven derivatives was determined based on the determination of the minimum
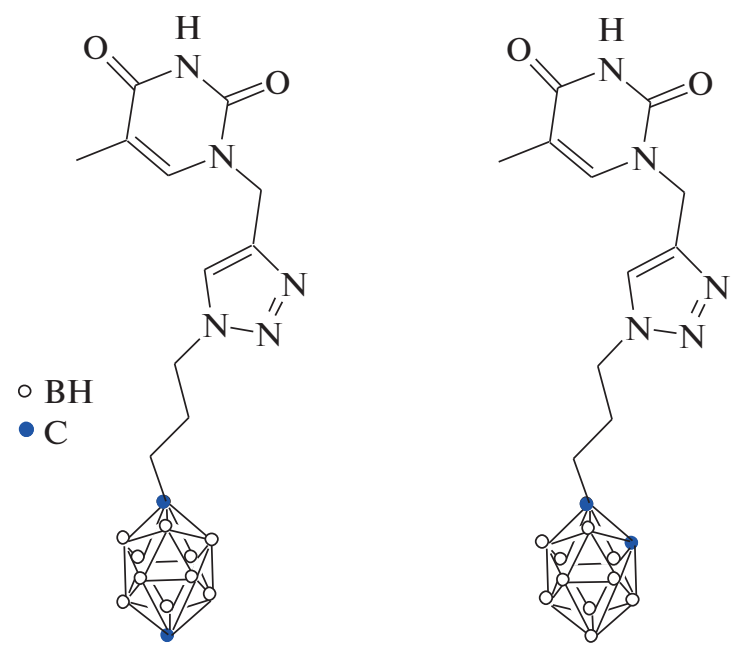

Fig. 18. Structure of carboranyl-containing thymine derivatives. 

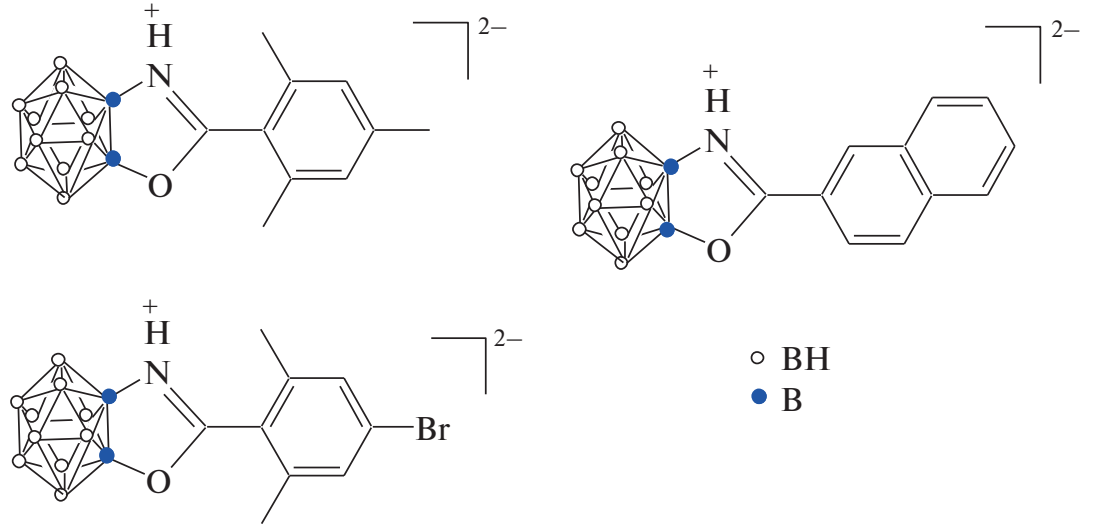

$\circ \mathrm{BH}$

- $\mathrm{B}$

Fig. 19. Derivatives of diboroxazoles containing the closo-dodecaborate anion.

inhibitory concentrations $\left(\mathrm{MIC}_{80}\right)$. The growth of $S$. aureus was suppressed with high selectivity in the presence of the compound with $\mathrm{Nu}=\mathrm{NH}_{3}$ at a concentration of $3.8 \mathrm{mg} / \mathrm{L}$. The authors note the absolute selective activity of the compound with $\mathrm{Nu}=$ $\mathrm{NH}_{2} \mathrm{CH}_{3}$ in inhibiting the growth of the filamentous fungus Trichosporon cutaneum.

A number of compounds containing carborane clusters have been tested for antiviral activity. In particular, a number of conjugates of para-carborane [78], ortho-carborane [79], and bis(1,2-dicarbollide)cobalt [80] with 5-ethynyl-uridine were obtained by the Sonogashir cross-coupling reaction of the corresponding boron-containing terminal alkyne and 5 -iodine nucleoside. The structure of some compounds is shown in Fig. 22. The activity of the compounds obtained against viruses HCMV, EMCV, HPIV-3, HSV-1 was studied; compounds have shown low to moderate cytotoxicity in several cell lines. The most active compound is 5-[(1,12-dicarba-closo-dodecaboran-2-yl)ethin-1-yl]-20-deoxyuridine (Fig. 22c); for this compound, an $\mathrm{IC}_{50}$ of $5.5 \mathrm{mM}$ with a selectivity index higher than 180 was found. It was found that the

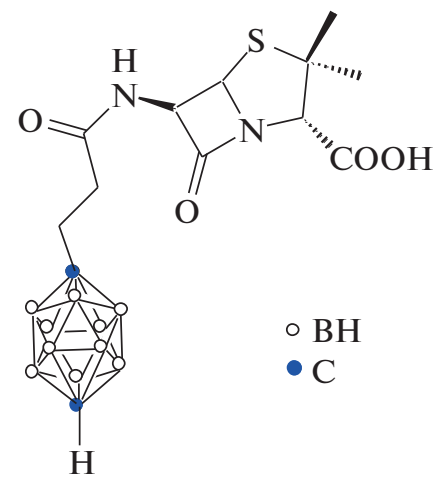

Fig. 20. Analog of penicillin G containing para-carborane. compound exhibits antiviral activity against HCMV and is not active against HSV-1, HPIV-3, or EMCV [78].

In addition, conjugates based on closo-dodecaboratoamines were obtained as universal synthons, including bis(closo-dodecaborates), conjugates of closo-dodecaborate with lipids and with the unnatural nucleoside 8-aza-7-deaza-2'-deoxyadenosine (Fig. 23) [81]. The compounds showed low or moderate toxicity, but were ineffective against viruses. No activity was found against HSV-1, HPIV-3, EMCV, VSV, and HMCV.

It was recently discovered [82-84] that a new class of bis(1,2-dicarbollide)cobalt derivatives is a potent specific and selective competitive inhibitor of HIV protease (Fig. 24). The most active compound (Fig. 24a) exhibits high activity against HIV and has no toxic effect on the cell culture $\left(\mathrm{IC}_{50}=100 \mathrm{nM}\right)$ [82].

Related derivatives of bis(1,2-dicarbollide)cobalt were studied [83, 84] (Figs. 24b-24d). Substituted metallacarboranes are potent specific and selective competitive inhibitors of wild-type and mutated HIV PR protease inhibitors. The authors explain their ability to inhibit many protease inhibitor-resistant PR species due to their novel way of binding at binding sites through participation in dihydrogen bonds and

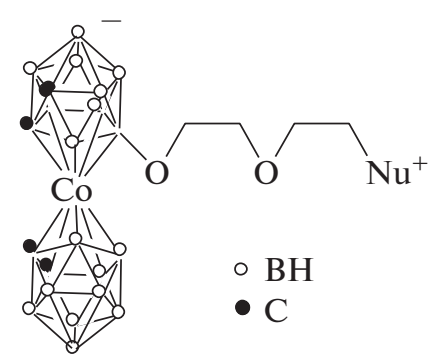

Fig. 21. Derivatives of $\mathrm{N}$-alkylammonium 8 -diethylene glycol-bis(dicarbollide)cobalt. $\mathrm{Nu}$ is $\mathrm{NH}_{3}, \mathrm{NH}_{2} \mathrm{CH}_{3}$, $\mathrm{NH}\left(\mathrm{CH}_{3}\right)_{2}, \quad \mathrm{~N}\left(\mathrm{CH}_{3}\right)_{3}, \quad \mathrm{NH}_{2} \mathrm{C}_{2} \mathrm{H}_{5}, \quad \mathrm{NH}\left(\mathrm{C}_{2} \mathrm{H}_{5}\right)_{2}$, $\mathrm{N}\left(\mathrm{C}_{2} \mathrm{H}_{5}\right)_{3}$. 


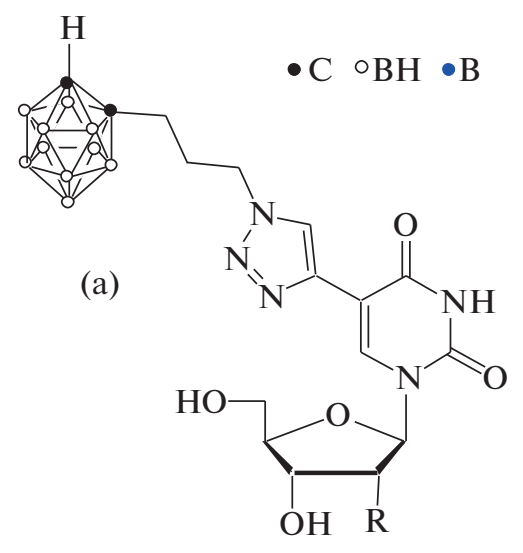

$\mathrm{R}=\mathrm{H}, \mathrm{OH}$ (b)

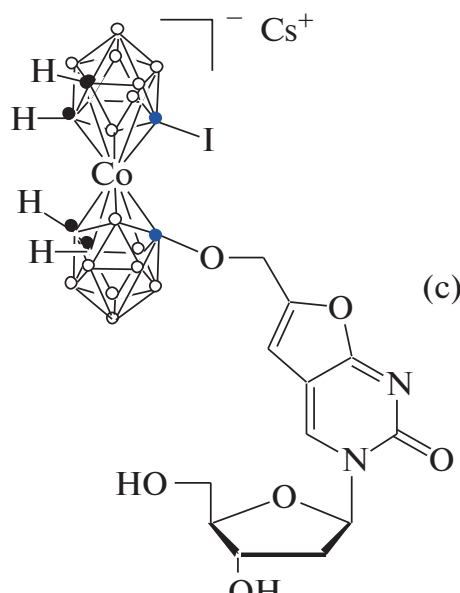

c)

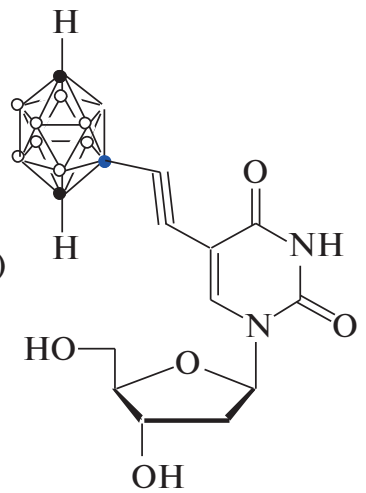

Fig. 22. Structure of nucleoside conjugates containing (a) ortho-carborane, (b) bis(1,2-dicarbollide)cobalt, and (c) para-carborane.

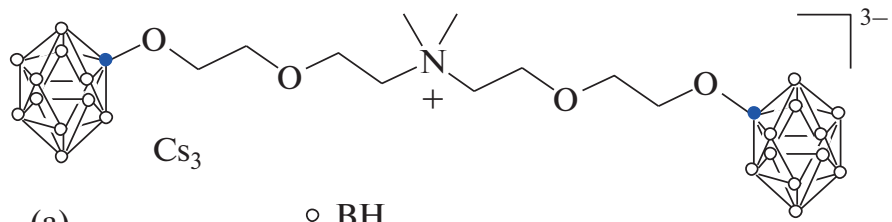

(a)

- $\mathrm{BH}$

(b)

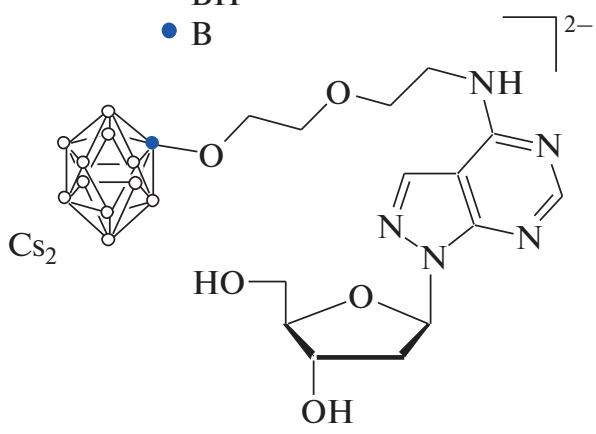

Fig. 23. Conjugates of the closo-dodecaborate anion with (a) lipids and (b) unnatural nucleosides.

their ability to regulate the position of the metallacarborane cage in the HIV PR substrate. The authors emphasize that boron clusters are promising pharmacophores for potent specific inhibition of drug-resistant HIV protease mutants.

The synthesis of a new inhibitor of neuraminidase, carborane-containing ester of carboxylic acid oseltamivir (Oseltamivir), has been described, its physicochemical and spectral characteristics have been reported [85] (Fig. 25). The carborane analog of oseltamivir was found to be an order of magnitude less active than its predecessor, the corresponding ethyl ester, which is an active ingredient in pharmaceuticals used in the prevention and treatment of influenza.

At the end of the review, we note several examples that justify the comparison of the pharmacological properties of inorganic and organic three-dimensional systems, which include boron and adamantane clusters. Drawing analogies in the structures and properties of compounds is a tool necessary for the design of new compounds [86]. Study [87] compared the activity of phenyl derivatives of meta- and para-carborane with a similar derivative of adamantane (Fig. 26) in relation to binding to estrogen. Using the bioluminescence method, it was shown that the 4-phenyl-paracarborane derivative exhibits the highest activity among other carborane analogs and is 10 times more active than 17-estradiol. The 4-phenyl-para-carborane derivative exhibits transcriptional activity in the concentration range from $1 \times 10^{-10}$ to $1 \times 10^{-8} \mathrm{~mol}$, and its effect is comparable to that of a similar adamantane derivative (Fig. 26a). Estrogen receptor antagonists are widely used in the treatment of breast cancer. 


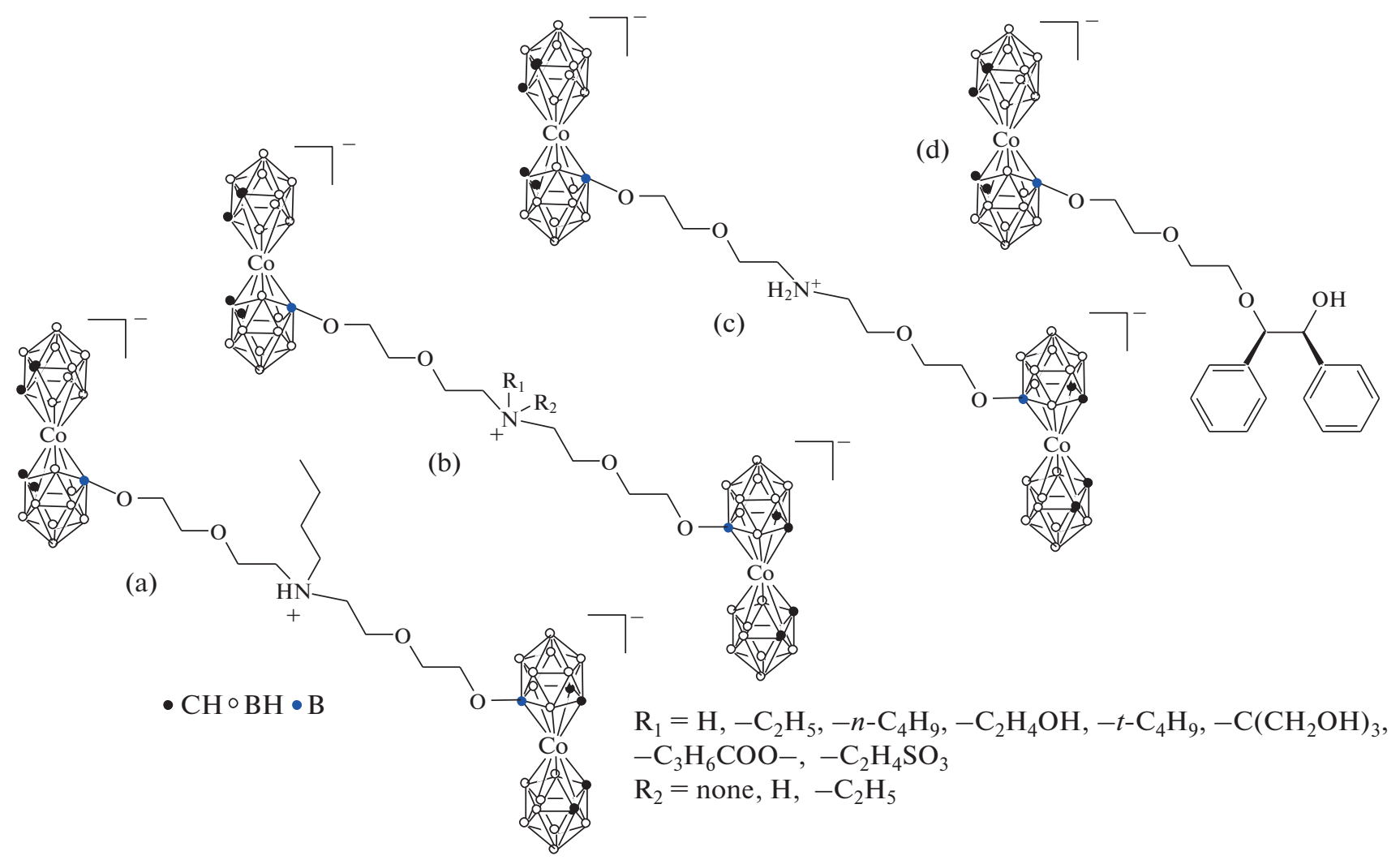

Fig. 24. Derivatives of bis(1,2-dicarbollide)cobalt with activity against HIV.

The authors [88] synthesized 48 analogues of the cell growth inhibitor Mycobacterium tuberculosis SQ109, in which the ethylenediamine linker is replaced by oxa, thia, or heterocyclic groups containing adamantane or 1,2-carborane. Some representatives of the compounds are shown in Fig. 27. Compounds were tested against M. tuberculosis (H37Rv and/or Erdman), M. smegmatis, Bacillus subtilis, Escherichia coli, Saccharomyces cerevisiae, Trypanosoma brucei and two human cell lines (human embryonic kidney HEK293T and hepatocellular carcinoma). The strongest activity was found against $T$. brucei, the causative agent of human African trypanosomiasis; this was found for 15 analogs of SQ109, which were more active than SQ109 in inhibiting cell growth, with an

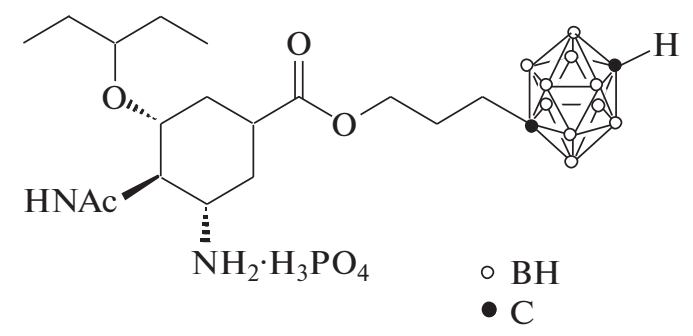

Fig. 25. Carborane analog of oseltamivir.
$\mathrm{IC}_{50}$ value of only $12 \mathrm{nM}(5.5 \mathrm{ng} / \mathrm{mL})$ and an index selectivity of $\sim 300$. Carboranes were less active against M. tuberculosis, but, surprisingly, had activity $\left(\mathrm{IC}_{50} \sim 2\right.$ $\mu \mathrm{g} / \mathrm{mL}$ ) against Gram-negative bacteria E. coli.

Authors [89] compared bioisosteres based on the same type of adamantane and ortho-, meta- and paracarborane derivatives and studied their antimalarial action (Fig. 28). It has been shown that the introduction of adamantane reduces the in vitro efficacy against Plasmodium falciparum in comparison with the parent phenyl compound, and the introduction of carboranes leads to its improvement; however, these changes contribute to a decrease in metabolic stability. The transition of closo-carboranes to the nido-structure leads to a decrease in the toxicity of the compounds, as well as their activity in comparison with closo-analogs.

In $[90,91]$, a derivative of the closo-decaborate anion $\left[\mathrm{B}_{10} \mathrm{H}_{9}-\mathrm{O}\left(\mathrm{CH}_{2}\right)_{4} \mathrm{C}(\mathrm{O})-\mathrm{His}-\mathrm{OMe}\right]^{2-}$ with the His-OMe functional group bound to the boron cluster anion by the spacer $\mathrm{O}\left(\mathrm{CH}_{2}\right)_{4}$ (Fig. 29b) was synthesized and the antiviral activity of its sodium salt against influenza A/Moscow/01/2009(H1N1)pdm09 virus was studied in vitro. It was shown that the compound has antiviral activity at 10 and $5 \mu \mathrm{g} / \mathrm{mL}$ and demonstrates the absence of cytotoxicity up to $160 \mu \mathrm{g} / \mathrm{mL}$. The activity of the target compound was compared 


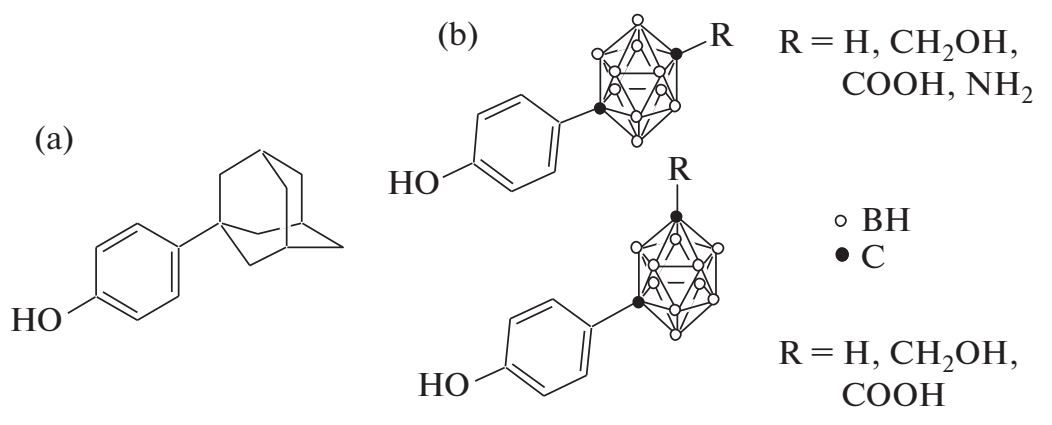

Fig. 26. Phenyl derivatives of (a) adamantane and (b) meta- and para-carborane.

with the adamantane-containing analog, a rimantadine derivative (Fig. 29a), and its higher activity was shown compared to $\mathrm{HCl} \cdot \mathrm{H}-\mathrm{His}-\mathrm{Rim}$ (the percentage of inhibition was 91.0 and $88.0 \%$ at concentrations of 5 and $10 \mu \mathrm{g} / \mathrm{mL}$ compared to 47 and $62 \%$ for the rimantadine derivative, respectively).

A quantum mechanical model of the $\left[\mathrm{B}_{10} \mathrm{H}_{9}-\right.$ $\left.\mathrm{O}\left(\mathrm{CH}_{2}\right)_{4} \mathrm{C}(\mathrm{O})-\mathrm{His}-\mathrm{OMe}\right]^{2-}$ anion was created, molecular docking was performed with a model of the transmembrane region of the M2 protein (PDB $2 \mathrm{KIH}$ ), and on the basis of the data obtained, the mechanism of action of the target compound was proposed [91].

The active study of new methods for the introduction of functional groups into boron cluster anions expands the possibilities for the design of new compounds, including those with physiologically active properties $[92,93]$.

\section{Molecular Model of a Viroporin Inhibitor}

At the end of the review, we would like to discuss a possible mechanism of action of cage compounds that have an inhibitory effect against influenza A viruses. Studies of the biological activity of adamantane derivatives arose almost simultaneously with the rapid

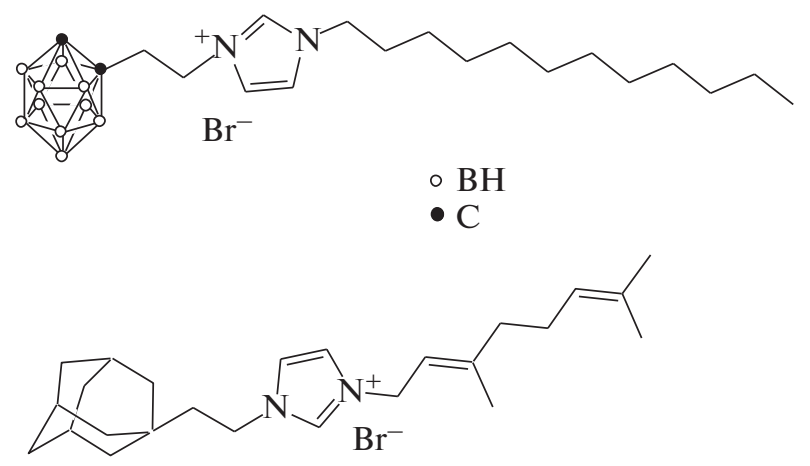

Fig. 27. Adamantane- and carborane-containing cell growth inhibitors of Mycobacterium tuberculosis SQ109. development of adamantane chemistry. As already noted, the first adamantane compound that found application in medicinal chemistry was amantadine (1-aminoadamantane), which has a high antiviral activity against influenza $A$. The subsequent resistance of viruses to adamantane preparations prompted researchers to study the mechanism of action, which is associated with inhibition of the function of the ionselective channel (proton pump) in the envelope of the virus. These transmembrane proteins, capable of forming conducting channels in the envelope of the viruses themselves or post-translationally in the organelles of the host cell, are called viroporins.

Viroporins are a group of proteins that are involved in many stages of the viral replication cycle, including promoting the release of viral particles from cells. These proteins also affect cellular functions, including the cellular visicle system, glycoprotein transport, and membrane permeability. The presence of viroporins is not a prerequisite for viral replication, but significantly increases the growth of virions. Viroporins, consisting of 60-120 amino acids, have a hydrophobic transmembrane domain that interacts with the lipid bilayer and disrupts its hexagonal packing. Some viroporins also contain other motifs, such as basic amino acid residues or a domain rich in aromatic amino acids, which give the protein the ability to interact with the interfacial lipid bilayer. Oligomerization of viroporin

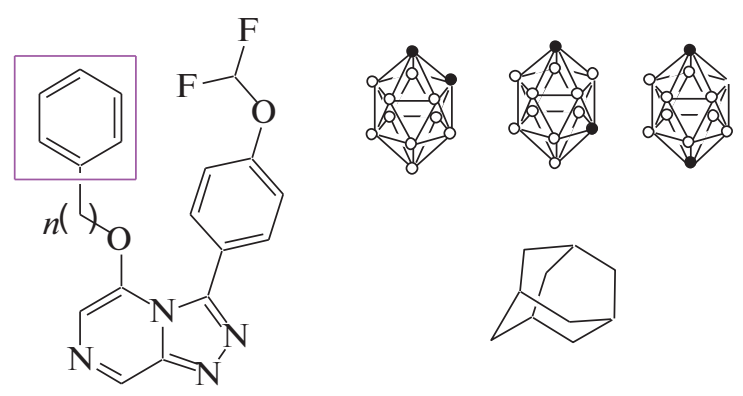

Fig. 28. Potential antiviral agents based on adamantane and carboranes. 
(a)

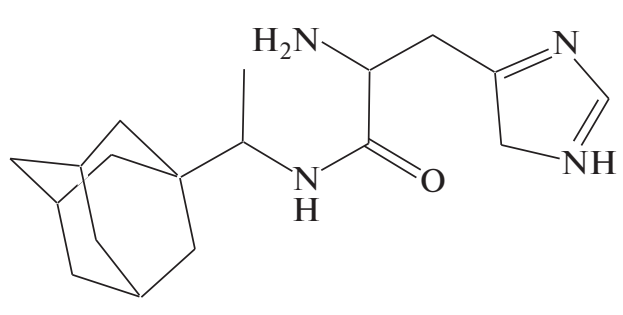

(b)

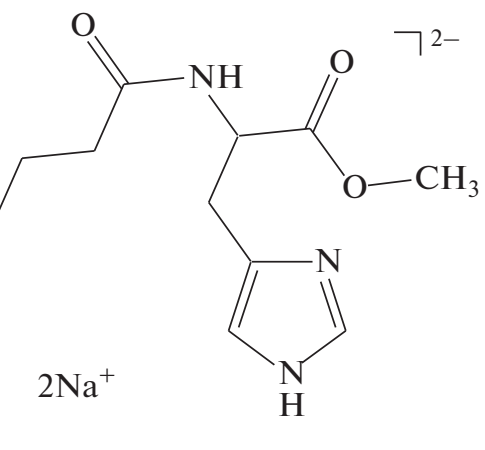

$\mathrm{H}$-His- $\mathrm{Rim} \cdot 2 \mathrm{HCl}$

$\mathrm{Na}_{2}\left[2-\mathrm{B}_{10} \mathrm{H}_{9} \mathrm{OC}_{4} \mathrm{H}_{8} \mathrm{CONHCH}(\mathrm{COOMe}) \mathrm{CH}_{2}(4-1 H\right.$-Imidazole $\left.)\right]$

Fig. 29. Aminoacid derivatives of (a) adamantane and (b) the closo-decaborate anion with antiviral activity.

leads to the formation of hydrophilic pores on the membranes of virus-infected cells. As the list of known viroporins grows steadily, recent research has focused on deciphering the actions of the viroporins of poliovirus $2 \mathrm{~B}$, alphavirus $6 \mathrm{~K}, \mathrm{HIV}-1 \mathrm{Vpu}$, hepatitis $\mathrm{C} \mathrm{p7}$, and influenza M2. All these proteins can enhance the penetration of ions and small molecules across membranes, depending on the concentration gradient [41].

A typical representative of tetrameric ion-selective viroporins is the M2 proton-conducting channel of the influenza A. The drug amantadine (Symmetrel, 1adamantylamine hydrochloride) was one of the first studied inhibitors of the M2 proton channel of the influenza A. It was used in clinical practice against the influenza A virus since 1966 [94]. In 1985, it was shown that some mutations in the hydrophobic sequence of the M2 protein can lead to virus resistance to amantadine and its analogue rimantadine (Flumantadine, 1-(1-adamantyl)ethylamine hydrochloride). These data suggested that the M2 protein may be a target for adamantane drugs, and in 1992 these assumptions were confirmed [95]. In 2020, the authors [96] put forward a hypothesis in their in silico calculations that amantadine blocks the ion channel of the SARS-CoV-2 virus. It is assumed that amantadine can interact via hydrogen bonds with the amino acid residues Phe26 and Ala22 of the protein viroporin E.

Viroporins are very conservative in their amino acid composition. Mutations in these proteins can lead to the nonviability of viruses; therefore, they are of interest as a therapeutic target for the development of new inhibitors of viroporin function [97].

It is known that viroporins are inhibited by ion channel blocking compounds such as amantadine, rimantadine, hexamethylene amiloride, and long chain derivatives of acyl imino sugars. At the moment, Australian and Chinese scientists are conducting the second stage of clinical trials of the synthetic drug BIT225 ( $N$-[5-(1-methyl-1H-pyrazol-4-yl)-napthalene-2-carbonyl]-guanidine)), which has shown the ability inhibit the functions of viroporins of the hepatitis C virus (HCV) and HIV-1 [42] (Fig. 30).

Inhibitors (blockers) of the function of the M2 protein of the influenza A virus, as a rule, consist of a hydrophobic part of the molecule (in the preparations of amantadine and rimantadine it is adamantane), connected to a polar functional group. In amantadine or rimantadine, the substituent is an amino or ethylamino group. The adamantyl residue can be replaced by other hydrophobic groups, including conjugated and spiroconjugated multicyclic alkanes, branched acyclic alkanes, terpene derivatives, and silanes [38, 39].

Moreover, a new class of positively charged molecules has been proposed, namely diazabicyclooctane derivatives with a constant charge of +2 , which block the diffusion of protons through the M2 ion channel. The states of ionization of histidine residues at position 37 at physiological pH values have been established by molecular dynamics methods. The charged molecule has an advantage over amantadine and rimantadine because it has a +2 charge, which creates a positive electrostatic potential barrier for the transport of hydrogen ions through the M2 ion channel in addition to the steric barrier [40].

Thus, not only neutral cage hydrocarbons and heterocycles can be used to block ion-conducting channels, but also charged polyhedra, such as closo-borate anions and related carboranes.

Summarizing the data on the antiviral activity of various structures of scaffold derivatives, it is possible to form a molecular model of a viroporin inhibitor. It is a three-dimensional cage core (neutral or carrying a general charge) (Fig. 31), which performs the function of a membranotropic carrier of the functional group. This role can be played by carbocyclic alkanes such as adamantane, norbornene, or fused and substituted aromatic systems such as boron cluster anions. On the other hand, the cage fragment is connected to a functional group that is capable of forming a non-covalent 
<smiles>N=C(N)NC(=O)c1nc(Cl)c(N)nc1N</smiles>

Amiloride<smiles>CN(C)c1nc(N)c(C(=O)NC(=N)N)nc1Cl</smiles><smiles>Cn1cc(-c2cccc3cc(C(=O)NC(=N)N)ccc23)cn1</smiles><smiles>N=C(N)NC(=O)c1nc(Cl)c(N2CCCCCC2)nc1N</smiles><smiles>CCCC</smiles><smiles>N=C(NC(=O)c1nc(Cl)c(N)nc1N)Nc1ccccc1</smiles>

Benzaml<smiles>OCCCCCCCCCN1CC(O)C(O)C(O)C1CO</smiles><smiles>OCC1C(O)C(O)C(O)CN1CCCCCCCCCC1CCCO1</smiles><smiles>OCC1C(O)C(O)C(O)CN1CCCCCCCCCc1ccccc1</smiles><smiles>NC12CC3CC(CC(C3)C1)C2</smiles><smiles>CC(N)C12CC3CC(CC(C3)C1)C2</smiles>

Amantadine

Rimantadine

Fig. 30. Structure of selected known inhibitors of viroporins (amantadine, rimantadine, hexamethylene amiloride (HMA) and long-chain derivatives of acyl-iminosugars).

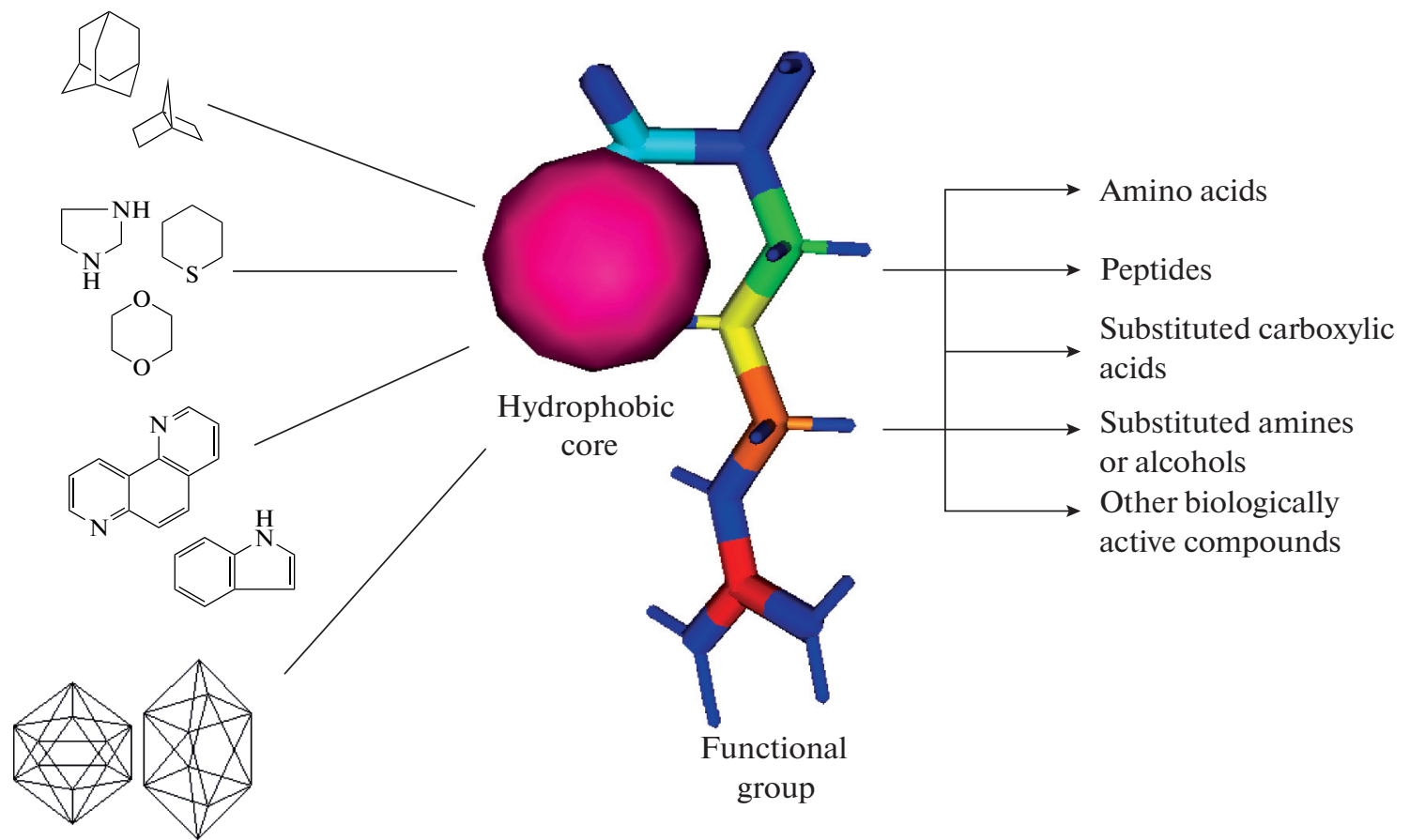

Fig. 31. Molecular model of an inhibitor of the function of viroporins.

interaction with the pore surface of the viroporin channel. Amino acids, peptides, and a number of other physiologically active compounds can act as a source of such groups.

\section{CONCLUSIONS}

Derivatives of cage structures, boron cluster anions and adamantane series compounds, have been considered. It has been found that the introduction of various 
functional groups allows one to obtain compounds inhibiting the replication of viruses, and also imparts other pharmaceutical properties to the target molecules. Analyzing the data presented, we can expect the appearance of antiviral properties in derivatives of the decahydro-closo-decaborate anion with side amino acids, peptides, and some other physiologically important compounds, since in this case the closodecaborate anion acts as a membranotropic carrier, which is consistent with the proposed inhibitor model. Thus, the discussed derivatives of boron cluster anions can be considered as a new class of objects with promising antiviral activity.

\section{FUNDING}

The reported study was funded by the Russian Foundation for Basic Research, project no. 20-13-50192.

\section{CONFLICT OF INTERESTS}

The authors declare that they have no conflicts of interest.

\section{REFERENCES}

1. M. Scholz and E. Hey-Hawkins, Chem. Rev. 111, 7035 (2011).

2. V. Ďordovič, Z. Tošner, and M. Uchman, et al., Langmuir 32, 6713 (2016). https://doi.org/10.1021/acs.langmuir.6b01995

3. N. N. Greenwood and A. Earnshaw, Chemistry of the Elements, 2nd ed. (Butterworth-Heinemann, 1997).

4. R. N. Grimes, Carboranes (Academic Press, London, 2016). https://doi.org/10.1016/B978-0-12-801894-1.09989-3

5. Boron Science: New Technologies and Applications, Ed. N. S. Hosmane (CRC Press, 2012).

6. Boron-Based Compounds: Potential and Emerging Applications in Medicine, Ed. by E. Hey-Hawkins, C. Viñas Teixidor (John Wiley \& Sons Ltd., 2018). https://doi.org/10.1002/9781119275602

7. K. Yu. Zhizhin, A. P. Zhdanov, and N. T. Kuznetsov, Russ. J. Inorg. Chem. 55, 2089 (2010). https://doi.org/10.1134/S0036023610140019

8. I. B. Sivaev, A. V. Prikaznov, and D. Naoufal, Collect. Czech. Chem. Commun. 75, 1149 (2010). https://doi.org/10.1135/cccc2010054

9. I. B. Sivaev, Russ. J. Inorg. Chem. 64, 955 (2019). https://doi.org/10.1134/S003602361908014X

10. I. B. Sivaev and V. I. Bregadze, Polyhedral Boron Hydrides in Use: Current Status and Perspectives (Nova Science Publishers Hauppauge, 2009).

11. A. V. Shmal'ko and I. B. Sivaev, Russ. J. Inorg. Chem. 64, 1726 (2019). https://doi.org/10.1134/S0036023619140067

12. I. B. Sivaev. Russ. J. Inorg. Chem. 66, 1289 (2021). https://doi.org/10.1134/S0036023621090151

13. R. Bruce King, Chem. Rev. 101, 1119 (2001). https://doi.org/10.1021/cr000442t
14. Z. Chen and R. B. King, Chem. Rev. 105, 3613 (2005). https://doi.org/10.1021/cr0300892

15. Z. Kazimierczuk, A. Gorska, T. Switaj, and W. Lasek, Bioorg. Med. Chem. Lett. 11, 1197 (2001).

16. K. Spilovska, F. Zemek, J. Korabecny, et al., Curr. Med. Chem. 23, 3245 (2016). https://doi.org/10.2174/0929867323666160525114026

17. N. D. Igumnova, E. Lemina, I. I. Bitiukova, et al., Farmakol. Toksikol. 51, 38 (1998).

18. Su-Mi Kim, Jong-Hyeon Park, Kwang-Nyeong Lee, et al. Antivir. Res. 96, 213 (2012). https://doi.org/10.1016/j.antiviral.2012.09.009

19. K. A. Agnew-Francisa and C. M. Williams, Synth. Catal. Adv. 358, 675 (2016).

20. M. S. Wassel, M. Wael, E. Gamal, et al., J. Appl. Vet. Sci. 5, 37 (2020).

21. D. Ao, H-C. Guo, S-Q. Sun, et al., PloS ONE 10, e0125828 (2015).

22. V. L. Andronova, Antibiot. Khimioter. 41, 26 (1996).

23. L. H. Lavrova, Zh. Org. Khim. 4, 761 (1974).

24. W. L. Davies, R. R. Grunert, R. F. Haff, et al., Science 144, 862 (1964).

25. K. Spilovska, F. Zemek, J. Korabecny, et al., Curr. Med. Chem. 23, 3245 (2016). https://doi.org/10.2174/0929867323666160525114026

26. V. V. Zarubaev, E. L. Golod, P. M. Anfimov, et al., Bioorg. Med. Chem. 18, 839 (2010).

27. P. M. Anfimov, O. I. Kiselev, and V. V. Zarubaev, Molecular Medicine (Moscow, 2010) [in Russian].

28. V. A. Shibnev, T. M. Garaev, M. P. Finogenova, et al., Bull. Exp. Biol. Med. 153, 233 (2012).

29. V. A. Shibnev, P. G. Deryabin, T. M. Garaev, et al., Russ. J. Bioorg. Chem. 43, 517 (2017). https://doi.org/10.1134/S1068162017050132

30. P. G. Deryabin, T. M. Garaev, M. P. Finogenova, and A. I. Odnovorov, Voprosy Virus. 64, 268 (2019). https://doi.org/10.36233/0507-4088-2019-64-6-268-273

31. T. M. Garaev, A. I. Odnovorov, A. A. Lashkov, et al., Adv. Pharm. Bull. 22, 700 (2021). https://doi.org/10.34172/apb.2021.079

32. M. Yu. Shchelkanov, V. A. Shibnev, M. P. Finogenova, et al., Voprosy Virusol. 59, 37 (2014).

33. T. M. Garaev, A. I. Odnovorov, E. S. Kirillova, et al., Vopr. Virusol. 65, $16(2020)$. https://doi.org/10.36233/0507-4088-2020-65-1-16-20

34. I. Stankova, K. Chuchkov, R. Chayrov, et al., Int. J. Pept. Res. Ther. 26, 1781 (2020). https://doi.org/10.1007/s10989-019-09983-4

35. P. E. Aldrich, E. C. Hermann, and E. Walter, J. Med. Chem. 14, 535 (1971).

36. N. Tsuzuki, T. Hama, and M. Kawada, J. Pharm. Sci. 83, 481 (1994).

37. Litvinov V.P. // Khim. Geterotsikl. Soedin. 50, 12 (2002).

38. J. Wang, C. Ma, H. Jo, et al., J. Med. Chem. 56, 2804 (2013).

39. J. Wang, C. Ma, G. Fiorin, et al., J. Am. Chem. Soc. 133, 12834 (2011).

40. Y. N. Vorobjev, Mol. Biol. 54, 281 (2020). https://doi.org/10.1134/S0026893320020168 
41. M. E. Gonzalez and L. Carrasco, FEBS Lett. 552, 28 (2003).

42. G. Khoury, G. Ewart, C. Luscombe, et al., AIDS Res. Ther. 13, 7 (2016).

43. A. Corrias, G. Ennas, A. Musinu, et al., Chem. Mater. 5, 1722 (1993).

44. Ali Fayaz, Narayan S. Hosmane, Yinghuai Zhu, et al., Molecules 25, 828 (2020).

45. I. B. Sivaev and V. I. Bregadze, Eur. J. Inorg. Chem. 1433 (2009).

46. L. N. Goswami, L. Ma, Sh. Chakravarty, et al., Inorg. Chem. 52, 1694 (2013). https://doi.org/10.1021/ic3017613

47. K. Fink and M. Uchman, Coord. Chem. Rev. 431, 213684 (2021).

https://doi.org/10.1016/j.ccr.2020.213684

48. J. Fanfrlik, M. Lepsik, D. Horinek, et al., ChemPhys Chem 7, 1100 (2006).

https://doi.org/10.1002/cphc.200500648

49. A. Buzharevski, S. Paskaš, M. B. Sárosi, et al., Sci. Rep. 10, 4827 (2020).

50. M. F. Hawthorne, Angew. Chem., Int. Ed. Engl. 32, 950 (1993).

51. M. Kugler, J. Nekvinda, J. Holub, et al., ChemBioChem 22, 2741 (2021).

52. B. Grüner, J. Brynda, Das V., et al., ChemPlusChem 86, 352 (2021). https://doi.org/10.1002/cplu.202000723

53. D. Alberti, A. Michelotti, A. Lanfranco, et al., Sci. Rep. 10, 19274 (2020). https://doi.org/10.1038/s41598-020-76370-1

54. A. V. Nelyubin, I. N. Klyukin, A. P. Zhdanov, et al., Russ. J. Inorg. Chem. 64, 1750 (2019). https://doi.org/10.1134/S0036023619140043

55. V. V. Avdeeva, E. A. Malinina, K. Yu. Zhizhin, et al., J. Struct. Chem. 60, 692 (2019). https://doi.org/10.1134/S0022476619050020

56. M. F. Hawthorne, K. Shelly, and F. Li, Chem. Commun. 547 (2002).

57. E. A. Malinina, V. V. Avdeeva, S. E. Korolenko, et al., Russ. J. Inorg. Chem. 65, 335 (2020). https://doi.org/10.1134/S003602362003002X

58. Yasuyuki Endo, Tomohiro Yoshimi, and Chisato Miyaura, Pure Appl. Chem. 75, 1197 (2003).

59. B. T. S. Thiruinamagal, Xiaobin B. Zhao, Bandyopadhyaya Achintya K., et al., Bioconjugate Chem. 17, 1141 (2006). https://doi.org/10.1021/bc060075d

60. T. Goto, K. Ohta, T. Suzuki, et al., Bioorg. Med. Chem. 13, 6414 (2005). https://doi.org/10.1016/j.bmc.2005.06.061

61. Endo Yasuyuki, Iijima Toru, Yamakoshi Yuko, et al., Bioorg. Med. Chem. Lett. 9, 3313 (1999). https://doi.org/10.1016/S0960-894X(99)00596-X

62. Emilia O. Zargham, Mason A. Christian, and Mark W. Lee, Jr., Int. J. Cancer Clin. Res. 6, 110 (2019). https://doi.org/10.23937/2378-3419/1410110

63. Endo Yasuyuki, Iijima Toru, Kagechika Hiroyuki, et al., Chem. Pharm. Bull. 47, 585 (1999). https://doi.org/10.1248/cpb.47.585
64. T. Iijima, Y. Endo, M. Tsuji, et al., Chem. Pharm. Bull. 47, 398 (1999). https://doi.org/10.1248/cpb.47.398

65. K. Bednarska, A. B. Olejniczak, B. A. Wojtczak, et al., ChemMedChem 5, 749 (2010). https://doi.org/10.1002/cmdc.201000075

66. Z. J. Leśnikowski and R. F. Schinazi, Org. Chem. 58, 6531 (1993). https://doi.org/Leśnikowski.1021/jo00076a001

67. Z. J. Leśnikowski, J. Shi, and R. F. Schinazi, J. Organomet. Chem. 581, 156 (1999). https://doi.org/10.1016/S0022-328X(99)00129-1

68. Tetsushi Totani, Katsutoshi Aono, Kiyoe Yamamoto, and Katsuya Tawara, J. Med. Chem. 24, 1492 (1981). https://doi.org/10.1021/jm00144a024

69. G. Oros, I. Ujvary, and R. J. Nachman, Amino Acids 17, 357 (1999).

70. W. Swietnicki, W. Goldeman, M. Psurski, et al., Int. J. Mol. Sci. 22, 6762 (2021). https://doi.org/10.3390/ijms22136762

71. Y. Zheng, W. Liu, Y. Chen, et al., Organometallics 36, 3484 (2017). https://doi.org/10.1021/acs.organomet.7b00426

72. D. Różycka, M. Korycka-Machała, A. Żaczek, et al., Pharmaceuticals 12, 465 (2020). https://doi.org/10.3390/ph13120465

73. T. Popova, A. Zaulet, F. Teixidor, et al., J. Organomet. Chem. 747, 229 (2013). https://doi.org/10.1016/j.jorganchem.2013.07.006

74. A. Adamska, A. Rumijowska-Galewicz, A. Ruszczynska, et al., Eur. J. Med. Chem. 121, 71 (2016).

75. Y. J. Sun, J. L. Zhang, Y. B. Zhang, et al., Chemistry 24, 10364 (2018).

76. D. Różycka, Z. Leśnikowski, and A. Olejniczaka, J. Organomet. Chem. 881, 19 (2019). https://doi.org/10.1016/j.jorganchem.2018.11.037

77. E. Kvasničková, J. Masák, J. Čejka, et al., J. Organomet. Chem. 827, 23 (2017).

78. M. Białek-Pietrasa, A. B. Olejniczak, E. Paradowska, et al., J. Organomet. Chem. 798, 99 (2015).

79. M. Białek-Pietrasa, A. B. Olejniczak, E. Paradowska, et al., J. Organomet. Chem. 865, 166 (2018).

80. I. Kosenko, I. Ananyev, A. Druzina, et al., J. Organomet. Chem. 849-850, 142 (2017).

81. J. Laskova, A. Kozlova, M. Białek-Pietrasa, et al., J. Organomet. Chem. 807, 29 (2016).

82. P. Cígler, M. Kozísek, P. Rezácová, et al., Proc. Natl. Acad. Sci. USA 102, 15394 (2005). https://doi.org/10.1073/pnas.0507577102

83. M. Kozísek, P. Cígler, M. Lepšík, et al., J. Med. Chem. 51, 4839 (2008). https://doi.org/10.1021/jm8002334

84. P. Rezácová, J. Pokorná, J. Brynda, et al., J. Med. Chem. 52, 7132 (2009). https://doi.org/10.1021/jm9011388

85. A. Adamska, A. B. Olejniczak, K. Zwolinski, et al., Acta Pol. Pharm. 69 (6), 1218 (2012).

86. I. B. Sivaev, Russ. J. Inorg. Chem. 65, 1854 (2020). https://doi.org/10.1134/S0036023620120165 
87. Endo Yasuyuki, Iijima Toru, Yamakoshi Yuko, et al., J. Med. Chem. 42, 1501 (1999). https://doi.org/10.1021/jm9900725

88. Kai Li, Yang Wang, Gyongseon Yang, et al. ACS Infect. Dis. 1, 215 (2015). https://doi.org/10.1021/acsinfecdis.5b00026

89. E. G. Tse, S. D. Houston, C. M. Williams, et al., J. Med. Chem. 63, 11585 (2020). https://doi.org/10.1021/acs.jmedchem.0c00746

90. T. M. Garaev, T. V. Grebennikova, V. V. Avdeeva, et al., Pat. RF RU 2749006 S1 (Published June 2, 2021).

91. T. M. Garaev, V. V. Avdeeva, A. P. Zhdanov, et al., Proceedings of the XXVIII International Chugaev Conference on Coordination Chemistry, Tuapse, 2021, p. 364.

92. A. V. Nelyubin, N. A. Selivanov, A. Yu. Bykov, et al., Russ. J. Inorg. Chem. 65, 795 (2020). https://doi.org/10.1134/S0036023620060133
93. A. V. Nelyubin, I. N. Klyukin, A. P. Zhdanov, et al., Russ. J. Inorg. Chem. 66, 139 (2021). https://doi.org/10.1134/S0036023621020133

94. J. L. Thomaston, N. F. Polizzi, A. Konstantinidi, et al., J. Am. Chem. Soc. 140, 15219 (2018).

95. C. Wang, K. Takeuchi, L. H. Pinto, et al., J. Virol. 67, 5585 (1993).

96. G. E. A. Abreu, M. E. H. Aguilar, D. H. Covarrubias, and F. R. Duran, Med. Hypotheses 140, 109755 (2020).

https://doi.org/10.1016/j.mehy.2020.109755

97. S. D. Griffin, L. P. Beales, D. S. Clarke, et al., FEBS Lett. 535, 34 (2003).

Translated by V. Avdeeva 